\title{
Caracterização de vulcânicas adakíticas e cálcio-alcalinas no greenstone belt do rio Itapicuru, Bahia: petrogênese e implicações geodinâmicas
}

\author{
Alberto Ruggiero $^{1}$ \& Elson Paiva Oliveira ${ }^{2}$
}

\begin{abstract}
Resumo Novos dados geoquímicos para as rochas vulcânicas da Unidade Maria Preta, Greenstone Belt do Rio Itapicuru, revelaram a presença de dois grupos distintos: um de rochas com afinidade adakítica e outro cálcio-alcalina. A suíte adakítica ocorre na porção oeste da Unidade Maria Preta e é caracterizada por altos valores de $\mathrm{Sr} / \mathrm{Y}, \mathrm{Ti} / \mathrm{Y}_{\mathrm{N}}>1$ e pelo enriquecimento em elementos de baixo potencial iônico (LFSE) em relação aos de elevado potencial iônico (HFSE) e também pelo moderado fracionamento dos elementos terras raras. A suíte cálcio-alcalina, que aflora na porção leste, apresenta baixas razões $\mathrm{Sr} / \mathrm{Y}, \mathrm{Ti} / \mathrm{Y}_{\mathrm{N}}<1$, menor fracionamento de elementos terras raras e anomalias negativas de Eu. Dados de isótopos de Sm-Nd, recalculados para (2170 Ma) forneceram valores de $\varepsilon_{\mathrm{Nd}}$ de $+4,78 \mathrm{a}+2,55$ para a suíte adakítica e de $+1,37 \mathrm{a}+1,90$ para a suíte cálcio-alcalina, sugerindo que as duas suítes podem ter sido geradas em contexto de zona de subduç̧ão. Os dois grupos vulcânicos não se relacionam por cristalização fracionada e provavelmente foram derivados de fontes distintas (diferentes razões iniciais $\mathrm{Nd}$ ). A geoquímica das vulcânicas cálcio-alcalinas foi atribuída à fusão da cunha do manto metassomatizado por fluídos liberados a partir de uma crosta oceânica subductada, seguido por fracionamento de plagioclásio no magma. Por outro lado, a geoquímica dos adakítos requer fusão de meta-basaltos hidratados com granada e/ou hornblenda residual. Esta suíte não apresenta indícios de interação significativa com a cunha do manto, como em adakitos atuais, face aos baixos valores de $\mathrm{Cr}$ e Ni. A distribuição geográfica das duas suítes sugere subducção de crosta oceânica para oeste, caso sejam da mesma idade.
\end{abstract}

Palavras-chave: Vulcânicas félsicas, Adakitos, Cálcio-alcalinas, Geoquímica, Greenstone belt do Rio Itapicuru.

\begin{abstract}
Characterization of adakitic and calc-alkaline volcanic rocks in the Rio Itapicuru Greenstone Belt, Bahia: Petrogenesis and geodynamic implications. New geochemical data for andesites and dacites of the Maria Preta Unit, Rio Itapicuru Greenstone Belt, revealed two distinct geochemical groups: one of adakitic affinity and another calc-alkaline. The adakitic suite, localized to the west in the unit, is characterized by high values of $\mathrm{Sr} / \mathrm{Y}, \mathrm{Ti} / \mathrm{Y}_{\mathrm{N}}>1$; it shows enrichment in LFSE (Low Field Strength Elements) relative to HFSE (High Field Strength Elements) and moderate rare earth elements fractionation. The calc-alkaline suite shows low $\mathrm{Sr} / \mathrm{Y}$ ratios, lower rare earth elements fractionation and negative Eu anomalies. It also shows high abundances of incompatible elements (Y, Zr, Th) and high $\mathrm{Cr}$ and Ni concentrations. The most likely mechanism of formation for the calc-alkaline rocks is partial melting of mantle peridotite hydrated by fluids released from the subducting slab, followed by plagioclase fractionation. The two suites cannot be linked to each other by fractional crystallization and have probably derived from distinct magmas (different initial Nd ratios). The adakite geochemical features require partial melt of hydrous metabasalts at depths high enough to stabilize garnet+hornblende as the residual phase. This suite does not show any significant interaction with the mantle wedge as inferred from its low $\mathrm{Cr}$ and $\mathrm{Ni}$ abundances when compared to Cenozoic adakites. $\mathrm{Sm}-\mathrm{Nd}$ isotope data indicated high positive $\varepsilon_{\mathrm{Nd}(\mathrm{T})}$ for the adakites $(+4.8$ to +2.5$)$ and slightly lower values for the calc-alkaline suite $\left(\varepsilon_{\mathrm{Nd}(\mathrm{T})}+1.9\right.$ to +1.4$)$. These data indicate a juvenile magma input to form the UMP volcanics. If the two volcanic suites are of the same age, then their geographical position suggests subduction of the oceanic slab to the west.
\end{abstract}

Keywords: Felsic volcanics, Adakites, Calc-alkaline, Geochemistry, Rio Itapicuru greenstone belt.

INTRODUÇÃO Neste trabalho, é descrita pela primeira vez a ocorrência de duas suítes vulcânicas distintas no Greenstone Belt do Rio Itapicuru (GBRI), no nordeste do Cráton São Francisco: uma de afinidade adakítica e outra cálcio-alcalina. Essas rochas ocorrem na região central do referido greenstone belt e foram reunidas na Unidade Maria Preta. No Brasil, apenas no Greenstone
Belt Rio das Velhas já foi reportada a ocorrência de rochas vulcânicas adakíticas (Silva et al. 2000).

Adakitos são rochas ígneas com elevados valores de $\mathrm{Sr} / \mathrm{Y}, \mathrm{La} / \mathrm{Yb}$ e elementos de baixo potencial iônico relativamente aos elementos de elevado potencial iônico (Martin et al. 2005). Elas foram primeiramente descritas por Defant \& Drummond (1990) para desig-

1 - Universidade Estadual de Campinas, Programa de Pós Graduação em Geociências, Campinas (SP), Brasil.

E-mail: alberto.ruggiero@hotmail.com

2 - IG-UNICAMP, Departamento de Geologia e Recursos Naturais, Campinas (SP), Brasil. E-mail: elson@ige.unicamp.br 
nar andesitos e dacitos de alto $\mathrm{MgO}$. Ao contrário da maioria dos magmas cálcio-alcalinos de arco (basaltos, andesitos, dacitos e riolitos), formados pela fusão de manto peridotítico metassomatizado por fluídos (Gill 1981), os magmas adakíticos são formados pela fusão de basaltos hidratados em pressões suficientemente altas para estabilizar granada+anfibólio no restito e fundir plagioclásio (Rapp \& Watson 1995). Martin (1999) sugere que as condições atuais para formar adakitos é a fusão de crosta oceânica mais jovem que 30 milhões de anos, ou seja, fusão de crosta recém-formada, processo este que ocorre geralmente quando uma dorsal mesooceânica é consumida em uma zona de subducção. Nesta situação, a crosta oceânica encontra-se quente o suficiente para atingir o campo de fusão, que ocorre em pressões acima de 6 kbar e temperaturas superiores a $800^{\circ} \mathrm{C}$ (Rapp et al. 1991).

Se nas condições geotérmicas atuais os adakitos são raros, no Arqueano e no Paleoproterozóico, quando o gradiente geotérmico da Terra era mais acentuado, as condições necessárias para a geração de adakitos eram mais comuns. Martin \& Moyen (2002) afirmam que as séries TTGs (tonalito, trondhjemito e granodiorito) de alto $\mathrm{Al}_{2} \mathrm{O}_{3}$ são os equivalentes arqueanos dos adakitos, e que a mudança na composição deste magma ao longo do Arqueano é evidência direta do esfriamento da Terra.

Assim como no GBRI, em outros continentes existem vulcânicas adakíticas associadas com vulcânicas cálcio-alcalinas (e.g. Morris \& Witt 1997, Samsonov et al. 2005). A presença de dois tipos de magmas geoquimicamente distintos e próximos entre si sugere condições geodinâmicas distintas para a formação desses magmas.

Com o objetivo de avaliar os mecanismos e as fontes de geração destas duas suítes vulcânicas no GBRI são discutidos neste trabalho novos dados de elementos maiores, traço e terras raras, e de isótopos de $\mathrm{Nd}$.

CONTEXTO GEOLÓGICO REGIONAL O Greenstone Belt do Rio Itapicuru é uma unidade litotectônica do Bloco Serrinha, localizado na porção nordeste do Cráton do São Francisco (Fig. 1). De acordo com Mascarenhas (1979), Kishida (1979), Kishida \& Riccio (1980), Davison et al. (1988) e Silva (1992), o GBRI é compartimentado da base para o topo em três principais unidades litoestratigráficas:

- Unidade Vulcanica Máfica (UVM): Ocorre por todo o greenstone e é composta por derrames basálticos maciços a almofadados intercalados com rochas sedimentares pelíticas e químicas.

- Unidade Vulcânica Félsica (UVF): derrames andesíticos a dacíticos intercalados com pelitos, ritmitos, arenitos, arenitos arcosianos e conglomerados. Encontram-se também rochas piroclásticas representadas por brechas, aglomerados, ignimbritos e tufos.

- Unidade Sedimentar Vulcanoclástica (USV): composta por sequências turbidíticas intercaladas com sedimentos químicos e rochas epiclásticas.

Essa seqüência vulcano-sedimentar foi metamorfisada na fácies xisto-verde, porém na borda de domos granito-gnáissicos atingiu a fácies anfibolito (Silva 1992). Estruturalmente está organizada em uma

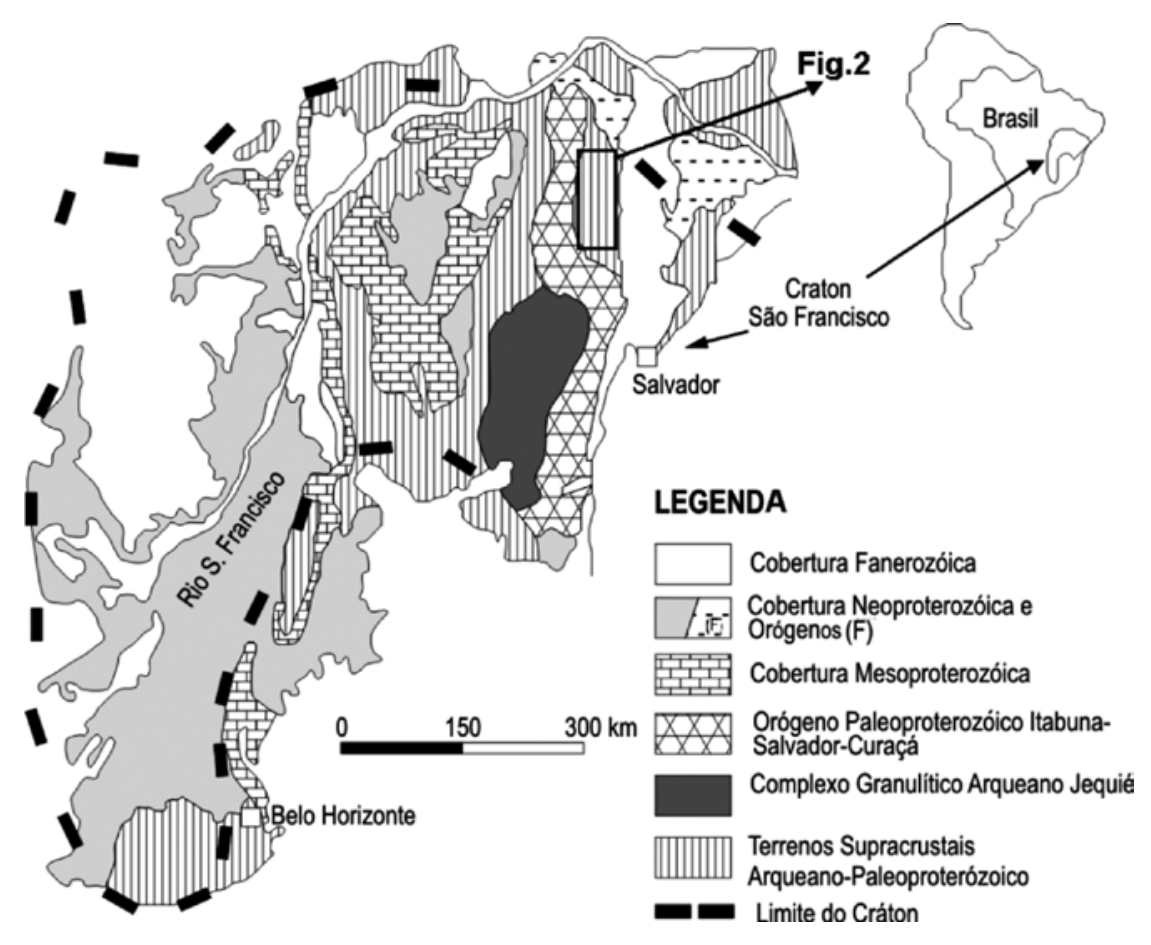

Figura 1 - Localização do Bloco Serrinha no nordeste do Cráton do São Francisco. Adaptado de Oliveira et al. (2004a). 
sucessão de sinclinais e anticlinais limitados por zonas de cisalhamento regionais, as quais têm cinemática sinistral e orientação N-S na porção centro-norte e E-W na porção sul do GBRI. Dois eventos deformacionais principais afetaram a seqüência (Alves da Silva 1994, Chauvet et al. 1997): D1 - caracterizado por cavalgamentos para SE, preservado na porção sul do GBRI, e D2- resultado da progressão de D1 para uma tectônica transcorrente que gera as grandes zonas de cisalhamento N-S sinistrais, as quais são um pouco posteriores ao alojamento de domos granito-gnáissicos sin-tectônicos.

Mineralizações Auríferas O GBRI é bastante conhecido por suas mineralizações auríferas (e.g. Xavier \& Foster 1999, Silva et al. 2001, Mello et al. 2006). Os depósitos de ouro no GBRI são do tipo lode orogenético e ocorrem em zonas de cisalhamento de pequeno a médio porte, nas porções sul (Distrito da Fazenda Brasileiro) e norte (Distrito da Fazenda Maria Preta). No primeiro distrito (Fig. 2), as mineralizações estão associadas a diversas gerações de veios de quartzo, em brechas hospedadas nos basaltos tholeiíticos e em gabros da UVM, e em menor quantidade nas vulcânicas intermediárias a ácidas da UVF e nos depósitos turbidíticos. No distrito da Fazenda Maria Preta (Fig. 2), os depósitos auríferos também estão associados a veios de quartzo e brechas que se hospedam nas lavas andesíticas e dacíticas da Unidade Maria Preta, bem como em seus equivalentes subvulcânicos. As paragêneses hidrotermais são carbonato, clorita, ankerita, pirita e arsenopirita (Rocha Neto \& Pedreira 1994, Silva et al 2001, Mello et al 2006, Yamana Gold Inc., 2007 com. verb.).

Modelos Geotectônicos Duas propostas foram sugeridas para o contexto geotectônico do GBRI. Segundo Silva (1991, 1992) e Silva et al. (2001), a unidade máfica do GBRI pode ter-se formado em uma bacia de back-arc desenvolvida sobre uma crosta continental arqueana; em seguida um arco continental, instalado a leste, seria o gerador do magmatismo intermediário a félsico bem como provedor dos sedimentos. Neste modelo, o Complexo Granulítico Caraíba (e.g. Figueiredo 1982), localizado a oeste do GBRI, no orógeno Itabuna-Salvador-Curaçá, seria o arco relacionado à bacia de back-arc. Entretanto, com o avanço dos dados geocronológicos, esta hipótese não é mais sustentável porque os gnaisses granulíticos do Complexo Caraíba têm idade entre $2695 \mathrm{Ma}$ e $2634 \mathrm{Ma}$ (Silva et al. 1997), ou um pouco mais novos na região da mina de Caraíba (2570 Ma cf. Oliveira et al 2010), enquanto aos basaltos do GBRI é atribuída idade de 2209 Ma (Silva 1996).

Por outro lado, Alves da Silva (1994) sugere que os basaltos do GBRI foram gerados em uma bacia do tipo marginal. Mais recentemente, Donatti Filho \& Oliveira (2007) e Oliveira et al. (2007) levantam a possibilidade de parte dos basaltos do GBRI ter origem em um rifte intracontinental, sucedido por abertura de crosta oceânica. Oliveira et al. (2004a) e Barrueto (1997) propõem a existência de um arco intra-oceânico entre 2130 e 2127 Ma (batólitos de Barrocas e Teofilândia,
Mello et al. 2006), seguido de colisão continental há cerca $2109 \mathrm{Ma}$ (Carvalho \& Oliveira 2003) que pode ter continuado até cerca de 2076-2072 Ma, quando o metamorfismo regional atingiu o seu clímax (Silva et al. 1997, Oliveira et al. 2004b, Mello et al. 2006). As mineralizações auríferas, ao menos na Fazenda Brasileiro, formaram-se entre 2054-2049 Ma (Vasconcelos \& Becker 1992, Mello et al. 2006).

Granitos Granitóides estão presentes em grande parte do GBRI (Fig. 2). Ocorrem intrusivos na maioria das litofácies e possuem natureza ácida a intermediária (Rios et al. 1998). Cruz Filho et al. (2005) propuseram uma classificação dos granitóides em corpos: i) tonalítico-trondhjemítico-granodioríticos, ii) cálcio-alcalinos, iii) alcalinos e/ ou ultrapotássicos e iv) domos gnáissico-migmatíticos.

Os tonalitos, trondhjemitos e granodioritos (TTGs) são representados pelos plútons Nordestina, Trilhado, Barrocas e Teofilândia. O domo de Nordestina ocorre no limite noroeste do GBRI e é o maior corpo granítico do GBRI (Cruz Filho et al. 2003). Sua geoquímica pode ser atribuída à fusão de crosta oceânica subductada ou fusão de crosta máfica inferior espessada magmaticamente (Cruz Filho et al. 2005). O granitóide Trilhado localiza-se $2 \mathrm{~km}$ a oeste da Unidade Maria Preta e trata-se de um pequeno corpo granodiorítico com formato losangular intrudido nos metabasaltos da Unidade Vulcânica Máfica. Os domos de Barrocas e Teofilândia localizam-se na porção sul do GBRI, e atualmente são interpretados como registros de um arco intra-oceânico (Barrueto 2002, Oliveira et al. 2004a).

Os granitóides cálcio-alcalinos são representados pelos maciços de Eficéias, Quijingue, Cipó e Morro do Lopes. Exibem maiores valores de $\mathrm{Al}_{2} \mathrm{O}_{3}$ e de elementos compatíveis, bem como razão $\mathrm{Sr} / \mathrm{Y}<40$ quando comparadas com os TTGs.

Os granitóides alcalinos ultra-potássicos ocorrem no limite oeste do GBRI e no embasamento, e são representados pelos corpos de Cansanção, Morro do Afonso, Agulhas, Pintado e Bananas. Geralmente não estão deformados e apresentam formatos circulares. Possuem afinidades shoshoníticas (Cansanção) e alcalino-potássica (Morro do Afonso, Agulhas, Bananas e Pintado). O grupo é composto por rochas sieníticas, monzoníticas e monzodioríticas (Rios 2002).

Os domos gnáissico-migmatíticos são geralmente alongados na direção norte-sul e possuem formas elipsoidais. São representados pelos domos de Ambrósio, Pedra Alta, Salgadália e Poço Grande (Rios et al. 1998).

Evolução Geocronológica Os trabalhos mais recentes sobre a geocronologia das rochas do GBRI são os de Silva (1996), Rios (2002), Silva et al. (2001), Oliveira et al. (2004a) e Mello et al. (2006). Uma síntese desses dados é apresentada na tabela 1.

Os dados geocronólogicos referentes à UVF foram primeiramente obtidos por Brito Neves et al. (1980) em isócrona de referência $\mathrm{Rb}-\mathrm{Sr}$ de $2.080 \mathrm{Ma} \pm$ 90 Ma. Posteriormente, Gaál et al. (inédito) apresentaram idade U-Pb 2.178 $\pm 12 \mathrm{Ma}$. Silva (1992), utilizando 


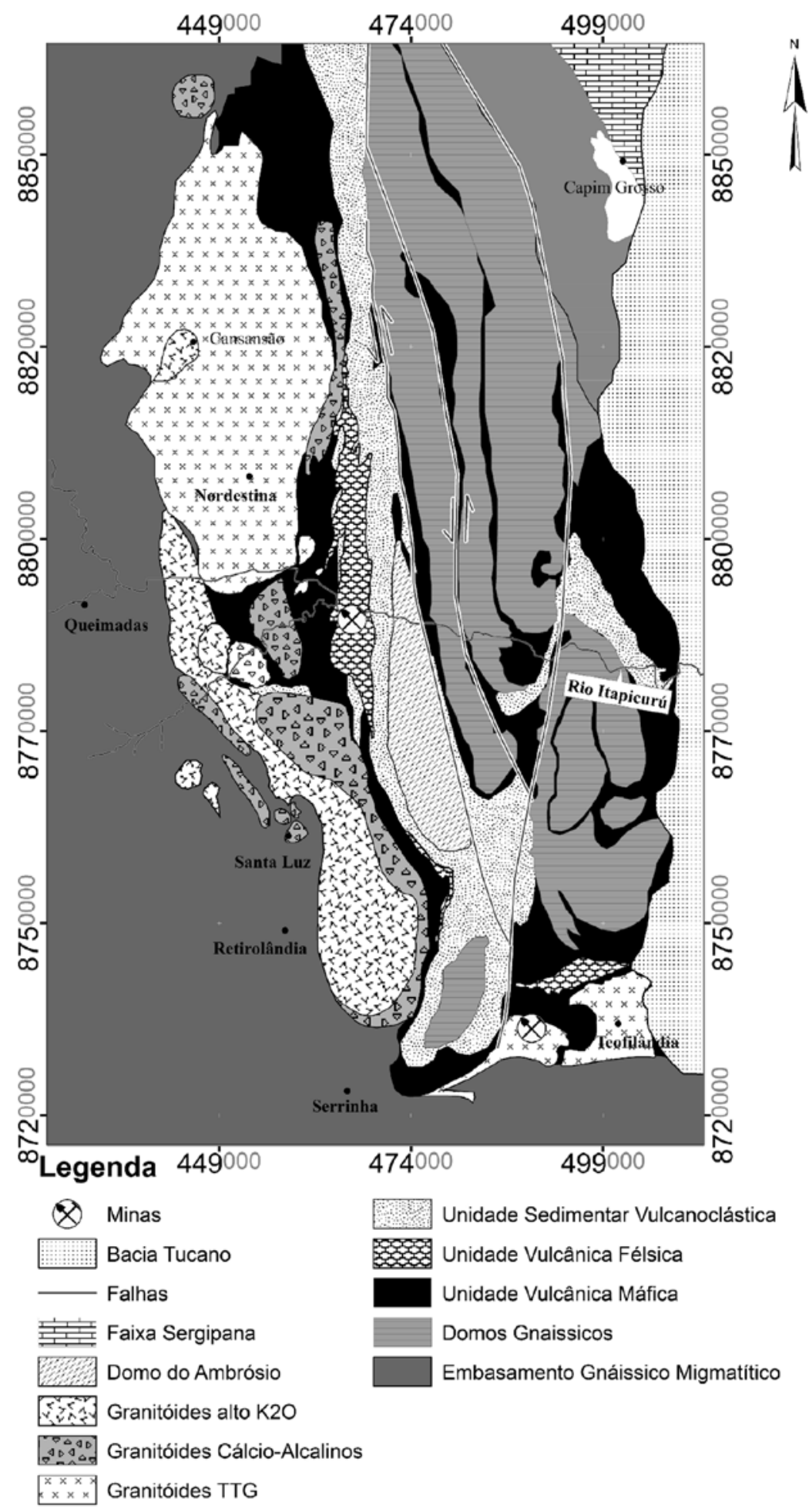

Figura 2 - Mapa geológico do Greenstone Belt do Rio Itapicuru e adjacências. A mina localizada na porção sul é a de Fazenda Brasileiro, no centro norte é a Fazenda Maria Preta. Modificado de Rocha Neto \& Pedreira (1994).

isócrona $\mathrm{Pb}-\mathrm{Pb}$ em rocha total gerou idade semelhante $2.170 \pm 60 \mathrm{Ma}$.

Estudos Geoquímicos Prévios A Unidade Vulcânica Félsica já foi investigada geoquimicamente. Alguns autores já identificaram o caráter cálcio-alcalino para as vulcânicas, baseados no enriquecimento em sílica, típi- co de séries cálcio-alcalinas de arco magmático (Kishida 1979, Silva 1992, Barrueto 1997). Kishida (1979) notou uma lacuna nos valores de sílica entre as duas unidades vulcânicas do GBRI: os basaltos têm valores médios de $50 \%$ de $\mathrm{SiO}_{2}$ e os andesitos e dacitos valores superiores a $60 \%$ de $\mathrm{SiO}_{2}$, e propôs origem diferente 
Tabela 1- Compilação das principais idades de rochas do greenstone belt do Rio Itapicuru.

\begin{tabular}{|c|c|}
\hline $2.209 \pm 60 \mathrm{Ma}$ & UVM - Vulcânicas máficas (Isócrona Pb-Pb em rocha total - Silva 1996) \\
\hline $2.170 \pm 60 \mathrm{Ma}$ & UVF- Vulcânicas Félsicas - (Isócrona Pb-Pb em rocha total - Silva 1996) \\
\hline $2.178 \pm 10 \mathrm{Ma}$ & UVF- Vulcânicas félsicas - (U-Pb - Gaál et al. inédito) \\
\hline $2.080 \mathrm{Ma}$ & UVF - Vulcânicas Félsicas - (Isócrona Rb-Sr - Brito Neves et al. 1980) \\
\hline $2.163 \pm 5 \mathrm{Ma}$ & Granitóide Eficeias (U-Pb diluição isotópica em zircões - Rios 2002) \\
\hline $2.155 \pm 9 \mathrm{Ma}$ & Granitóide Nordestina ( $\mathrm{Pb}-\mathrm{Pb}$ evaporação em zircões - Cruz Filho et al. 2003) \\
\hline $2.155 \pm 3 \mathrm{Ma}$ & Granitóide Quijingue (U-Pb diluição isotópica em zircões - Rios et al. 2002) \\
\hline $2.152 \pm 6 \mathrm{Ma}$ & Granitóide Trilhado (U-Pb SHRIMP em monazita - Mello et al. 2000) \\
\hline $2.142 \pm 47 \mathrm{Ma}$ & Intrusão Gabróica da Fazenda Brasileiro (isócrona Sm-Nd em rocha total - Pimentel \& Silva 2003) \\
\hline $2.130 \pm 7 \mathrm{Ma}$ & Granitóide Teofilândia (U-Pb SHRIMP em zircões - Mello et al. 2000) \\
\hline $2.127 \pm 5 \mathrm{Ma}$ & Granitóide Barrocas (evaporação de Pb em zircões - Chauvet et al. 1997) \\
\hline $2.110 \pm \mathrm{Ma}$ & Sienito Morro do Afonso. (U-Pb SHRIMP em zircões -Rios et al. 2007) \\
\hline $2.109 \pm 5 \mathrm{Ma}$ & Tonalito Itareru (U-Pb SHRIMP em zircões - Carvalho \& Oliveira 2003) \\
\hline $2.080-2.076 \mathrm{Ma}$ & $\begin{array}{l}\text { Pico do metamorfismo regional (Ar-Ar em hornblenda - Mello et al. 2006, U-Pb SHRIMP em } \\
\text { zircões - Oliveira et al. 2002) }\end{array}$ \\
\hline $2.080 \pm 2 \mathrm{Ma}$ & Domo Gnáissico Ambrósio (U-Pb SHRIMP em xenotima - Mello et al. 1999) \\
\hline $2.072 \pm 1 \mathrm{Ma}$ & $\begin{array}{l}\text { Intrusões graníticas tardi-tectônicas tipo Morro do Lopes (U-Pb diluição isotópica em zircões - } \\
\text { Rios et al. 2002) }\end{array}$ \\
\hline $2.054-2.049 \mathrm{Ma}$ & Mineralização aurífera (Ar-Ar muscovita - Vasconcelos \& Becker 1992, Mello et al. 2006) \\
\hline
\end{tabular}

para as duas unidades.

Segundo Silva $(1983,1992)$, as elevadas razões $\mathrm{La} / \mathrm{Yb}$ dessas rochas são indicativas de magmatismo cálcio-alcalino de arco de margem continental do tipo andina. Em modelagens geoquímicas, esta mesma autora sugeriu origem do magmatismo intermediário a félsico a partir de fusão parcial da unidade vulcânica máfica.

Os litotipos vulcânicos e subvulcânicos félsicos também foram caracterizados geoquimicamente por Barrueto (1997), porém as amostras coletadas nas cavaapresentaram caráter alcalino, enriquecidas em $\mathrm{Na}_{2} \mathrm{O}$.

\section{RESULTADOS}

Características de campo e petrografia A Unidade Maria Preta (UMP) foi cunhada por Silva et al. (2001) para reunir as rochas vulcânicas intermediárias a félsicas, subvulcânicas e piroclásticas (Fig. 3). Aqui, nós redefinimos a unidade, incluindo também rochas sedimentares associadas. Ela possui aproximadamente 250 $\mathrm{km}^{2}$ e forma alongada na direção NNW-SSE, com 48 $\mathrm{km}$ de comprimento e 5,2 km de largura. O Rio Itapicuru cruza a porção centro-sul da unidade. O limite ocidental da UMP é com basaltos da Unidade Vulcânica Máfica e o oriental é com rochas metassedimentares da Unidade Sedimentar Vulcanoclástica (Fig. 3).

ROCHAS META-VULCÂNICAS O conjunto de rochas vulcânicas é representado por andesito basáltico, andesito e dacito. Essas rochas ocorrem como derrames maciços (Fig. 4A e B) e geralmente sem deformação penetrativa. Quando deformados, o caimento da foliação é acentuado para oeste (em média $60^{\circ}$ ).

No entroncamento do Rio do Peixe com o Rio Itapicuru, também próximo ao contato da UMP com a UVM, a unidade possui, em sua base, derrames dacíticos cinza a cinza claro. Os dacitos são porfiríticos, com fenocristais de plagioclásio e quartzo, com média de $0,3 \mathrm{~mm}$ de diâmetro (Fig. 4C), imersos em matriz cinza afírica. Intercalados com os dacitos, ocorrem andesitos afaníticos, cinza escuro. Eles apresentam grande resistência ante a deformação e são intrudidos por um corpo subvulcânico diorítico (C1).

Ao noroeste do acampamento base da empresa Yamana Gold Inc., próximo ao contato com os basaltos basais, os derrames dacíticos são porfiríticos, bege a cinza escuro, com fenocristais de hornblenda imersos em matriz microcristalina de plagioclásio e quartzo. Os grãos de hornblenda são idiomórficos e podem atingir até $1 \mathrm{~cm}$ (Fig. 4D e 5A).

Grãos de plagioclásio ocorrem na matriz de algumas lavas, compostas por pequenos cristais orientados segundo o fluxo magmático, conferindo textura traquítica. $\mathrm{Na}$ maioria das lavas, o plagioclásio é representado por albita a oligoclásio. Feldspatos potássicos são escassos. Ocorrem também andesitos vesiculares, cujas vesículas podem estar preenchidas com calcita secundária (Fig. 5B).

Em algumas amostras de andesito, o quartzo apresenta cavidades em suas bordas, formando baías 


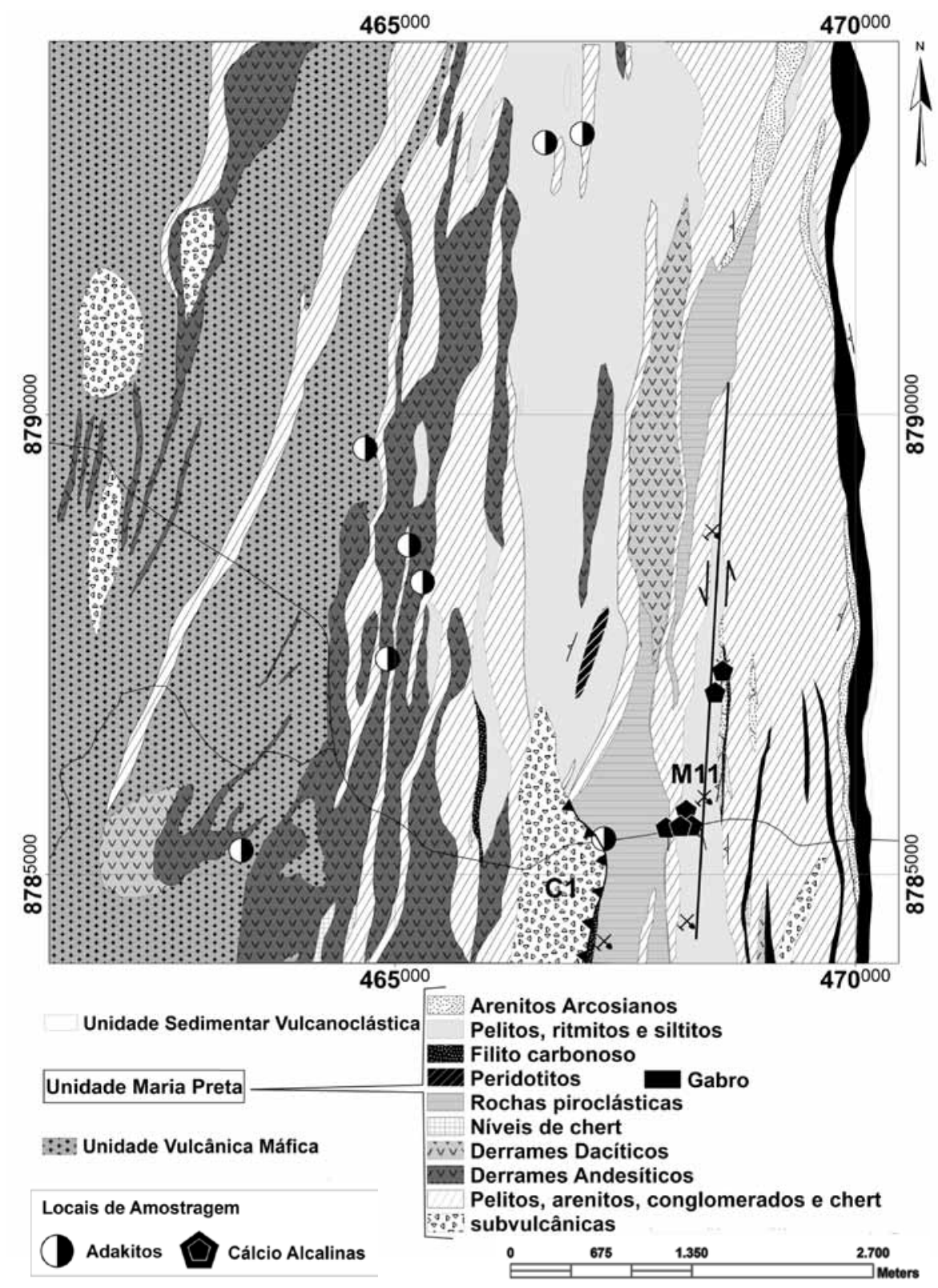

Figura 3 - Mapa geológico da Unidade Maria Preta, greenstone belt do Rio Itapicuru, com localização de amostras consideradas na seção de geoquímica. Modificado de Silva et al. (2001).

atribuídas à corrosão magmática (Fig. 5C).

Em alguns locais, os derrames foram muito alterados por soluções hidrotermais e mostram matriz composta por epidoto, clorita e sericita. Ocorrem fenocristais de quartzo euédrico límpido, monocristalino e sem extinção ondulante e inclusões. Os feldspatos, de maneira geral, apresentam-se repletos de inclusões de sericita e epidoto (Fig. 5D).

Geoquímica Foram realizadas análises para elementos maiores e traço utilizando o espectrômetro de Fluorescência de Raios X (Philips, PW 2404), do Laboratório de Geoquímica Analítica no Instituto de Geociências da UNICAMP. As amostras foram pulverizadas em moinho de ágata e analisadas através de pastilhas de vidro (elementos maiores) e pastilhas prensadas (elementos traço). Algumas amostras foram selecionadas também para análise dos elementos terras raras e outros elementos traço, cujos dados foram obtidos no ICP-MS do Instituto de Geociências da USP, segundo os procedimentos analíticos de Navarro (2004).

A seleção das amostras para geoquímica foi feita dando preferência às amostras frescas. Apesar da deformação regional que afetou as rochas do GBRI, há porções de baixa deformação onde as rochas encontram-se preservadas. Desta forma as amostras selecionadas para as análises são maciças, livres de veios e venulações. Os resultados analíticos são apresentados nas tabelas 2 e 3 onde as rochas vulcânicas foram separadas em cálcio-alcalinas e adakíticas com base na 


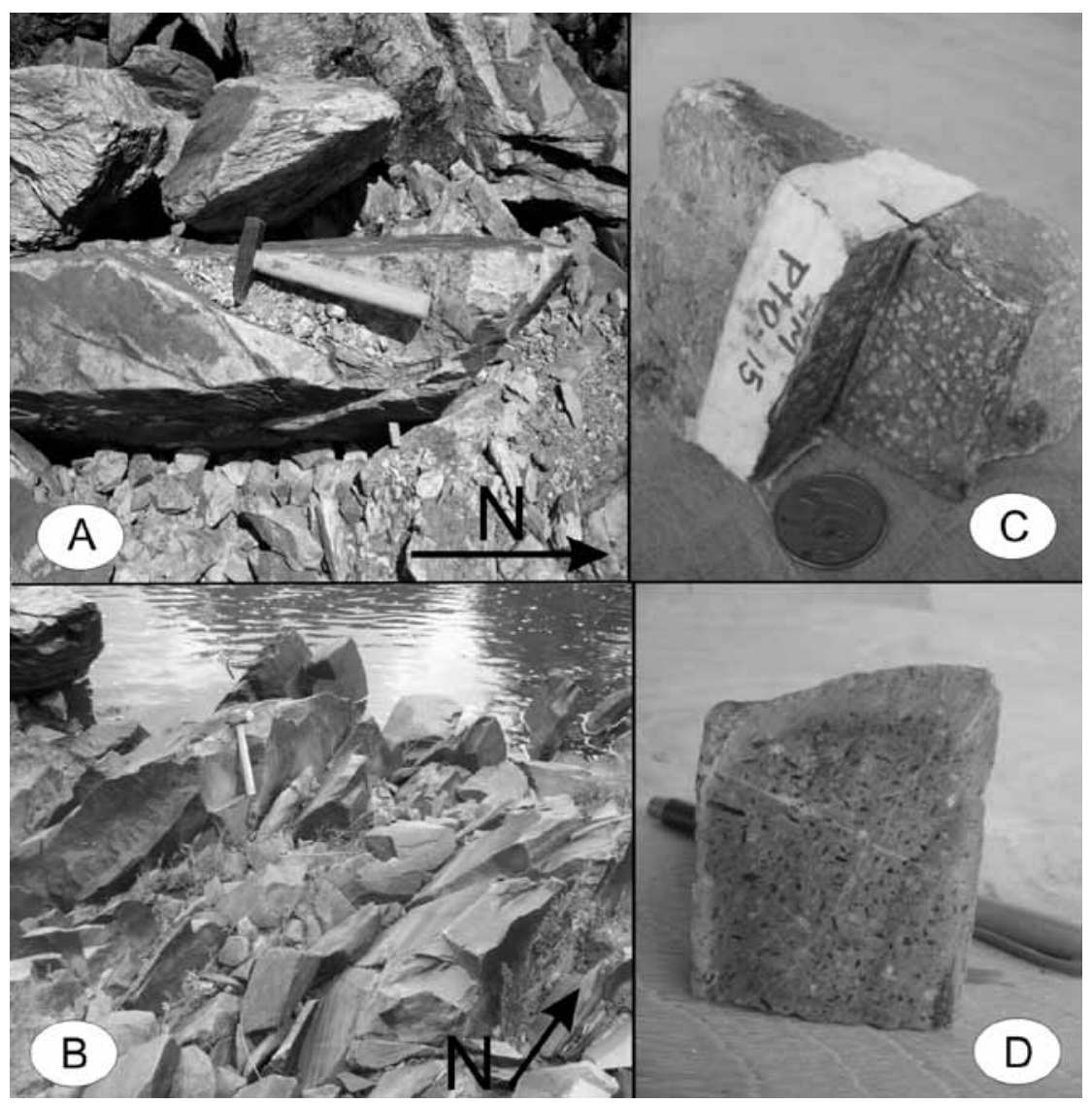

Figura 4 - Aspectos macroscópicos das vulcânicas da Unidade Maria Preta, A-Afloramento de dacito maciço afanítico, $B$-Afloramento de andesito afanitico, $C$-Andesito porfiritico com fenocristais de plagioclásio (Cálcio-Alcalino), D-Andesito porfirítico com fenocristais aleatórios de hornblenda (Adakítico).
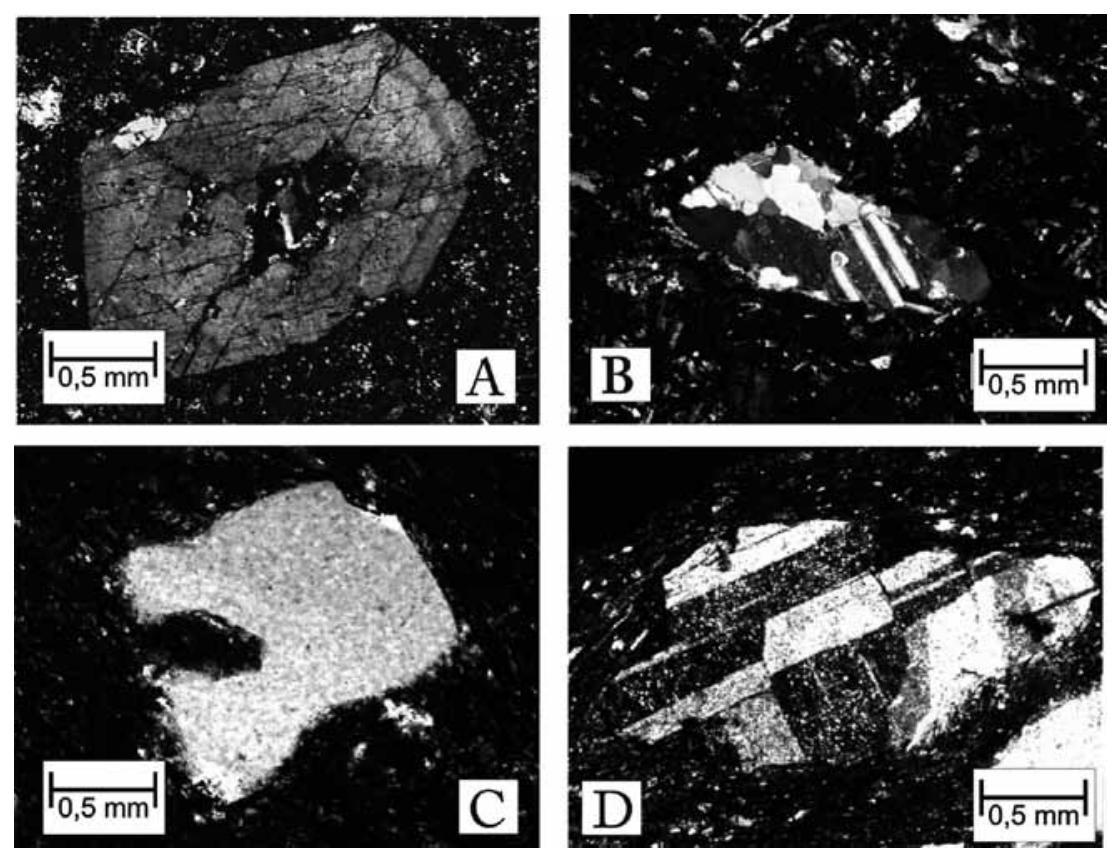

Figura 5 - Fotomicrografias das rochas vulcânicas da Unidade Maria Preta. A e C com nicóis descruzados. A- Fenocristal idiomórfico de hornblenda com zonamento e inclusões de opacos e quartzo; B-Amígdala de calcita em andesito; C- Quartzo com embaiamento por corrosão magmática. D-Fenocristais de plagioclásio parcialmente alterados. 
Tabela 2 - Resultados das análises de elementos maiores e traços para a Suite Adakítica e Cálcioalcalina, Unidade Maria Preta.

\begin{tabular}{|c|c|c|c|c|c|c|c|c|c|c|c|c|c|c|c|c|c|}
\hline & \multicolumn{12}{|c|}{ Suite Adakítica } & \multicolumn{5}{|c|}{ Suite Cálcioalcalina } \\
\hline & AM35 & AM98 & AM99 & AMJP2 & AM93 & AM34B & AM16 & AMJP1 & AM133 & AM18 & AM4 & AM46A & AM15 & AM14 & AMJP3 & AM37A & AM34A \\
\hline $\mathrm{SiO} 2$ & 58,1 & 60,58 & 60,67 & 61,51 & 62,13 & 63,16 & 63,66 & 64,15 & 64,82 & 64,92 & 66,99 & 52,56 & 6,15 & 60,32 & 61,29 & 63,31 & 70,99 \\
\hline $\mathrm{TiO} 2$ & 0,389 & 0,455 & 0,389 & 0,306 & 0,38 & 0,301 & 0,318 & 0,33 & 0,265 & 0,296 & 0,36 & 0,305 & 1,125 & 0,827 & 0,534 & 0,306 & 0,365 \\
\hline $\mathrm{A} 12 \mathrm{O} 3$ & 18,77 & 17,61 & 18,27 & 17,82 & 17,6 & 18,5 & 8,04 & 17,79 & 18,01 & 17,79 & 16,87 & 17,88 & 19,93 & 13,57 & 14,92 & 18,73 & 12,39 \\
\hline $\mathrm{Fe} 2 \mathrm{O} 3 \mathrm{t}$ & 6,65 & 5,16 & 5,04 & 3,88 & 4,57 & 3,72 & 3,76 & 3,27 & 2,83 & 2,56 & 1,92 & 6,27 & 6,76 & 6,07 & 7,07 & 3,5 & 5,09 \\
\hline $\mathrm{MnO}$ & 0,081 & 0,066 & 0,057 & 0,085 & 0,068 & 0,09 & 0,073 & 0,072 & 0,07 & 0,023 & 0,04 & 0,095 & 0,107 & 0,12 & 0,449 & 0,083 & 0,029 \\
\hline $\mathrm{MgO}$ & 1,44 & 1,9 & 2,2 & 1,2 & 1,62 & 1,2 & 1,32 & 1,33 & 0,98 & 0,98 & 1,68 & 2,29 & 2,48 & 3,85 & 2,99 & 1,23 & 0,71 \\
\hline $\mathrm{CaO}$ & 7,12 & 4,65 & 5,37 & 6,79 & 4,86 & 6,24 & 5,5 & 4,66 & 4,96 & 2,28 & 5,07 & 5,7 & 3,7 & 4,6 & 2,82 & 6,17 & 3,1 \\
\hline $\mathrm{Na} 2 \mathrm{O}$ & 2,73 & 5,12 & 4,34 & 3,71 & 4,5 & 3,45 & 4,3 & 4,14 & 4,3 & 5,53 & 5,76 & 7,68 & 6,06 & 4,02 & 3,08 & 4,22 & 4,74 \\
\hline $\mathrm{K} 2 \mathrm{O}$ & 1,68 & 2,3 & 1,89 & 1,24 & 57 & 1,56 & 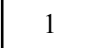 & 1,01 & 1,36 & 1,93 & 0,15 & 0,07 & 0,79 & 0,36 & 1,04 & 1,36 & 0,18 \\
\hline $\mathrm{P} 2 \mathrm{O} 5$ & 0,173 & 0,231 & 0,115 & 0,123 & 0,185 & 0,122 & 0,121 & 0,11 & 0,094 & 0,095 & 0,081 & 0,091 & 0,166 & 0,157 & 0,068 & 0,122 & 0,485 \\
\hline PF & 2,39 & 1,64 & 1,64 & 2,4 & 1,36 & 1,83 & 1,72 & 2,2 & 1,57 & 2,88 & 0,75 & 6 & 2,22 & 5,15 & 5,6 & 1,12 & 1,82 \\
\hline Soma & 99,5 & 097 & 100,0 & 99,1 & 99,8 & 1002 & 99,8 & 99,1 & 9,3 & 99,3 & 99,7 & 98 , & 99,5 & 99,0 & 99,9 & 100,2 & 99,9 \\
\hline $\mathrm{mg} *$ & 30,0 & 42,2 & 46,4 & 38,0 & 41,3 & 39,0 & 41,0 & 44,6 & 40,7 & 43,2 & 63,4 & 42,0 & 42,1 & 55,7 & 45,6 & 41,1 & 21,7 \\
\hline $\mathrm{Ba}$ & 1296,4 & 1031 & 892 & 839 & 1271 & 939,7 & 488,5 & 666 & 500 & 677,9 & 116,1 & 182,7 & 374 & 166,2 & 519 & 289,6 & 992 \\
\hline $\mathrm{Ce}$ & 24,5 & 20 & 11 & 13 & 13 & 11,8 & 11,2 & 13 & 11 & 6,4 & 3,4 & 27 & 16,8 & 23,8 & 41 & 27,3 & 6,8 \\
\hline $\mathrm{Cr}$ & 14,8 & 44 & 3 & 27,3 & 25 & 15,8 & 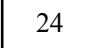 & 21,6 & 27,6 & 3,7 & 36,1 & 45 & 33,3 & 95,3 & 62 & 29,3 & 16,8 \\
\hline $\mathrm{Ga}$ & 23,8 & 19,3 & 20,6 & 18,4 & 20,2 & 19,5 & 21,1 & 21,2 & 20,5 & 20,6 & 23 & 17,4 & 22,6 & 19 & 26,2 & 8,7 & 20 \\
\hline $\mathrm{La}$ & 11,8 & . & 5 & 17 & 8 & 4,6 & 11,1 & 17 & 4 & 4 & 7,2 & 9,6 & 7,6 & 8,9 & 12 & 11 & 7,6 \\
\hline $\mathrm{Nb}$ & 2 & 2 & 1 & 1 & 2 & 2,1 & 0 & 7 & 2,4 & 2,6 & 2,2 & 8,1 & 7,6 & 7,7 & 7,7 & 4,1 & 2,2 \\
\hline $\mathrm{Nd}$ & 16 & 13 & 8 & $<8$ & 8 & 8 & 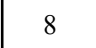 & $<8$ & 8 & 8 & 8 & 9,9 & 8,9 & 11,8 & 18 & 8 & 8 \\
\hline $\mathrm{Ni}$ & 6,6 & 13,5 & 11,1 & 16,6 & 8 & 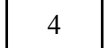 & 6,1 & 17,2 & 7,7 & 2,3 & 14,7 & 29,2 & 5,8 & 69,4 & 45 & 21,6 & 4,6 \\
\hline $\mathrm{Rb}$ & 27,9 & 3 & 3 & 35 & 35 & 30,7 & L & 36 & 38 & 45,8 & 3,1 & 1,9 & 33,6 & 15,1 & 24,7 & 8,2 & 26,7 \\
\hline $\mathrm{Sr}$ & 830,6 & 786 & 966 & 986 & 1315 & 922,8 & 933,3 & 959 & 879 & 540,1 & 479,6 & 165,8 & 336,1 & 235,1 & 328 & 90 & 1105 \\
\hline Th & $<1,5$ & 2,3 & 1,5 & $<1,5$ & 1,5 & 1,5 & 1,5 & $<1,5$ & 1,5 & 1,5 & 3,8 & 10,1 & 5 & 4,3 & 17,9 & 3,1 & 1,5 \\
\hline V & 63,7 & 89 & 63 & 51 & 69 & 51,2 & 63 & 53 & 33 & 40,7 & 57,2 & 52,7 & 87,5 & 40,3 & 231 & 30,7 & 44,9 \\
\hline Y & 6,9 & 9,9 & 5,6 & 5,1 & 7,6 & 5 & 5,9 & 5,1 & 3,8 & 3,8 & 4,9 & 22,8 & 21,1 & 19 & 23,7 & 37,2 & 4,6 \\
\hline $\mathrm{Zn}$ & 31,4 & 44 & 18,2 & 27,8 & 28,3 & 27,6 & 44,4 & 48 & 36 & 16,7 & 31,7 & 93,5 & 91,3 & 80,9 & 89 & 46,4 & 23,4 \\
\hline $\mathrm{Zr}$ & 76,9 & 89 & 67 & 28 & 86 & 79,2 & 106,3 & 68 & 106 & 100,2 & 80,7 & 182,6 & 129,4 & 139,5 & 198 & 115,9 & 80,6 \\
\hline $\mathrm{Sr} / \mathrm{Y}$ & 120,4 & 79,4 & 172,5 & 193,3 & 173,0 & 184,6 & 158,2 & 188,0 & 231,3 & 142,1 & 97,9 & 7,3 & 15,9 & 12,4 & 13,8 & 2,4 & 240,2 \\
\hline
\end{tabular}

Os valores de $\mathrm{mg}$ * foram calculados a partir da fórmula: $\mathrm{MgO} /(0.899 \mathrm{Fe} 2 \mathrm{O} 3 \mathrm{t}+\mathrm{MgO}$ em proporções moleculares $)$.

razão $\mathrm{Sr} / \mathrm{Y}$.

Elementos Maiores e Traço Em diagramas que empregam elementos maiores, como o de álcalis total $\left(\mathrm{Na}_{2} \mathrm{O}+\mathrm{K}_{2} \mathrm{O}\right)$ em relação à sílica (Fig. 6A), a variação demonstra que a maioria das rochas vulcânicas pertence à série cálcio-alcalina e posiciona-se nos campos de andesito e dacito. Apenas uma amostra situa-se no campo de basalto-traquiandesítico; ela é cálcio-alcalina e com o maior teor de $\mathrm{Na}_{2} \mathrm{O}$.

Usando-se o diagrama $\mathrm{SiO}_{2}$ vs $\mathrm{Zr} / \mathrm{TiO}_{2}$ (Fig. 6B), que utiliza elementos mais imóveis, quase todas amostras se posicionaram no campo de andesito e dacito, sendo que apenas uma amostra situa-se no campo 
Tabela 2 - Continuação.

\begin{tabular}{|c|c|c|c|c|c|c|c|}
\hline \multicolumn{8}{|c|}{ Cont. Suite Cálcioalcalina } \\
\hline & AM37B & AM46B & AM19B & AMJP4 & AM37C & AM19A & AM02 \\
\hline $\mathrm{SiO} 2$ & 65,08 & 65,62 & 66,47 & 66,95 & 67,74 & 70,66 & 72,58 \\
\hline $\mathrm{TiO} 2$ & 0,477 & 0,411 & 0,376 & 0,232 & 0,373 & 0,311 & 0,368 \\
\hline $\mathrm{A} 12 \mathrm{O} 3$ & 15,38 & 15,17 & 15,06 & 15,32 & 15,38 & 13,28 & 13,75 \\
\hline $\mathrm{Fe} 2 \mathrm{O} 3 \mathrm{t}$ & 5,16 & 5,12 & 4,6 & 2,29 & 4,65 & 4,52 & 4,49 \\
\hline $\mathrm{MnO}$ & 0,051 & 0,072 & 0,047 & 0,072 & 0,028 & 0,062 & 0,017 \\
\hline $\mathrm{MgO}$ & 1,13 & 1,41 & 1,42 & 1,28 & 0,92 & 1,62 & 1,53 \\
\hline $\mathrm{CaO}$ & 6,88 & 4,87 & 2,57 & 2,65 & 4,78 & 2,28 & 0,25 \\
\hline $\mathrm{Na} 2 \mathrm{O}$ & 3,37 & 3,39 & 5,66 & 2,13 & 3,96 & 4,31 & 4,29 \\
\hline $\mathrm{K} 2 \mathrm{O}$ & 0,13 & 0,66 & 0,65 & 2,69 & 0,56 & 0,36 & 0,84 \\
\hline $\mathrm{P} 2 \mathrm{O} 5$ & 0,114 & 0,076 & 0,07 & 0,037 & 0,068 & 0,066 & 0,06 \\
\hline $\mathrm{PF}$ & 1,76 & 2,46 & 2,66 & 5,6 & 1,57 & 2,38 & 1,76 \\
\hline Soma & 99,5 & 99,3 & 99,6 & 99,2 & 100,0 & 99,8 & 99,9 \\
\hline $\mathrm{mg} *$ & 30,3 & 35,3 & 38,0 & 52,6 & 28,2 & 41,5 & 40,3 \\
\hline $\mathrm{Ba}$ & 93,8 & 345 & 303,5 & 1641 & 239,3 & 265,4 & 369,7 \\
\hline $\mathrm{Ce}$ & 23,5 & 23,5 & 24,1 & 28 & 20,2 & 24,8 & 21,8 \\
\hline $\mathrm{Cr}$ & 68 & 29,2 & 23,1 & 8 & 32,3 & 60,5 & 40,1 \\
\hline $\mathrm{Ga}$ & 17,1 & 17,5 & 14 & 12,6 & 16,6 & 17,1 & 17,5 \\
\hline $\mathrm{La}$ & 14,5 & 19,1 & 15,5 & 21 & 18,2 & 11,7 & 11,8 \\
\hline $\mathrm{Nb}$ & 6 & 5,7 & 5,7 & 6,7 & 5,4 & 5,3 & 5,2 \\
\hline $\mathrm{Nd}$ & 8 & 10,6 & 8 & 15 & 8 & 8 & 8 \\
\hline $\mathrm{Ni}$ & 28 & 22,4 & 19,4 & 14,6 & 23 & 43,8 & 26,1 \\
\hline $\mathrm{Rb}$ & 6,4 & 24,3 & 23,4 & 74 & 25 & 17,3 & 34,2 \\
\hline $\mathrm{Sr}$ & 281,1 & 144,9 & 73,5 & 306 & 147,5 & 109,9 & 78,5 \\
\hline Th & 5,2 & 6,2 & 6,2 & 15,8 & 6,4 & 7,7 & 6,6 \\
\hline $\mathrm{V}$ & 52,6 & 43,4 & 26,2 & 23 & 35,4 & 32,2 & 49,7 \\
\hline Y & 22,7 & 22,5 & 18 & 12,1 & 17,8 & 17,3 & 15,6 \\
\hline $\mathrm{Zn}$ & 56,2 & 65 & 50,3 & 22 & 49,6 & 50,2 & 49,5 \\
\hline $\mathrm{Zr}$ & 161,7 & 143 & 139,5 & 180 & 145,3 & 136,3 & 126,8 \\
\hline $\mathrm{Sr} / \mathrm{Y}$ & 12,4 & 6,4 & 4,1 & 25,3 & 8,3 & 6,4 & 5,0 \\
\hline
\end{tabular}

de rochas alcalinas. Esta amostra é a mesma cálcioalcalina com elevado $\mathrm{Na}_{2} \mathrm{O}$, como comentado acima. $\mathrm{O}$ primeiro diagrama utiliza elementos que podem se remobilizar em processos pós-magmáticos, como alteração hidrotermal e metamorfismo, e consequentemente podem conduzir a uma classificação duvidosa. Em lâminas delgadas, a amostra destoante das demais apresenta plagioclásio quase inteiramente substituído por filossilicatos e epidoto, provavelmente por ação de fluidos hidrotermais, e por este motivo a consideramos não apropriada para os estudos petrogenéticos.

As lavas da Unidade Maria Preta formam dois grupos geoquímicos distintos a partir das diferentes concentrações dos elementos $\mathrm{SiO}_{2}, \mathrm{Na}_{2} \mathrm{O}, \mathrm{K}_{2} \mathrm{O}, \# \mathrm{mg}$ $\left(\mathrm{MgO} / \mathrm{MgO}+\mathrm{FeO}_{\mathrm{T}}\right.$ molecular), $\mathrm{Sr}, \mathrm{Y}, \mathrm{Zr}, \mathrm{Ti}, \mathrm{Ni}, \mathrm{Rb}$, $\mathrm{V}, \mathrm{Cr}$ e Ni: um com assinatura adakítica (Adk) e outro cálcio-alcalina (CA).

Os diagramas de variação de sílica (Fig. 7) exibem o comportamento distinto entre as duas suítes. Segundo o diagrama $\mathrm{K}_{2} \mathrm{O}$ vs $\mathrm{SiO}_{2}$ (Fig. 7A), todas as vulcânicas são de caráter cálcio-alcalino (Corriveau \& Gorton 1993), porém, segundo os campos de Le Maitre et al. (1989), a suíte cálcio-alcalina é de baixo potássio e a adakítica de médio potássio. Nos diagramas das figuras $7 \mathrm{~B}, 7 \mathrm{C}$ e $7 \mathrm{D}$ nota-se decréscimo de $\mathrm{Al}_{2} \mathrm{O}_{3}, \mathrm{TiO}_{2}$ e $\mathrm{MgO}$ com aumento de $\mathrm{SiO}_{2}$ nas duas suítes, embora elas apresentem linhas de tendência evolutiva distintas entre si. Esses alinhamentos são associados à evolução dos magmas por cristalização fracionada; as inclinações distintas entre as duas suítes indicam que os dois magmas evoluíram de maneira distinta.

Os diagramas de variação de óxidos contra o número de magnésio nas abscissas (\#mg) também exibem agrupamentos distintos entre as duas suítes (Figs. 7E, 7F, 7G e 7H).

Os adakitos apresentam valores de $\mathrm{SiO}_{2}$ no intervalo de 58 a $71 \%$ e, em relação à suíte cálcio-alcalina, valores superiores de $\mathrm{K}_{2} \mathrm{O}, \mathrm{Al}_{2} \mathrm{O}_{3}, \mathrm{Sr} / \mathrm{Y}$ e $\mathrm{Cr} / \mathrm{Ni}$ (Fig. 7).

A suíte cálcio-alcalina possui valores mais variados de $\mathrm{SiO}_{2}(\sim 52$ a $71 \%)$ e valores elevados de elementos de alto potencial iônico, tais como $\operatorname{Zr}(\sim 142$ ppm), Y ( 22 ppm) e $\mathrm{Nb}(\sim 5,9 \mathrm{ppm})$, além de teores mais elevados de $\mathrm{Ni}$ e $\mathrm{Cr}$ do que as rochas adakíticas.

As duas suítes vulcânicas apresentam características distintas quando lançadas em diagrama de multi-elementos normalizados ao manto primitivo (Fig. 8). Nesses diagramas, as rochas adakíticas mostram enriquecimento em $\mathrm{Ba}, \mathrm{Rb}, \mathrm{K}$ e Sr relativamente à suíte cálcio-alcalina. A anomalia negativa de $\mathrm{Nb}$ é muito mais pronunciada nos adakitos e uma clara anomalia positiva de Sr é observada nesta suíte (Fig. 8A). A suíte cálcio-alcalina apresenta anomalia negativa discreta de $\mathrm{Nb}$ e $\mathrm{Sr}$ e pronunciada de Ti. Os valores de $\mathrm{Ti}$ e $\mathrm{Zr}$ pouco diferem nas duas suítes, porém os valores de Y são bem menores na suíte adakítica, o que resulta em razões Ti/Y normalizadas distintas nas duas suítes. De fato, os adakitos possuem razão $(\mathrm{Ti} / \mathrm{Y})_{\mathrm{n}}>1$ (Fig. $8 \mathrm{~A}$ ), enquanto nas vulcânicas cálcio-alcalinas essa razão é inferior à unidade (Fig. 8B).

No diagrama de elementos terras raras normalizadas ao condrito é também possível notar diferenças entre as duas suítes (Fig. 9). A suíte cálcio-alcalina apresenta menor grau de fracionamento, expresso pela razão $(\mathrm{La} / \mathrm{Yb})_{n}$, com padrão mais aplainado $\left((\mathrm{La} / \mathrm{Yb})_{\mathrm{n}}=\right.$ $4,7)$ do que os adakitos $\left((\mathrm{La} / \mathrm{Yb})_{\mathrm{n}}=8,30\right)$. As anomalias de Eu também são diferentes nas duas suítes.

Os valores de Eu são geralmente afetados por cristalização fracionada de plagioclásio, que possui o 
Caracterização de vulcânicas adakíticas e cálcio-alcalinas no greenstone belt do rio Itapicuru, Bahia: petrogênese e implicações geodinâmicas

Tabela 3 - Resultados das análises de elementos terras raras e outros traços para a unidade Maria Preta.

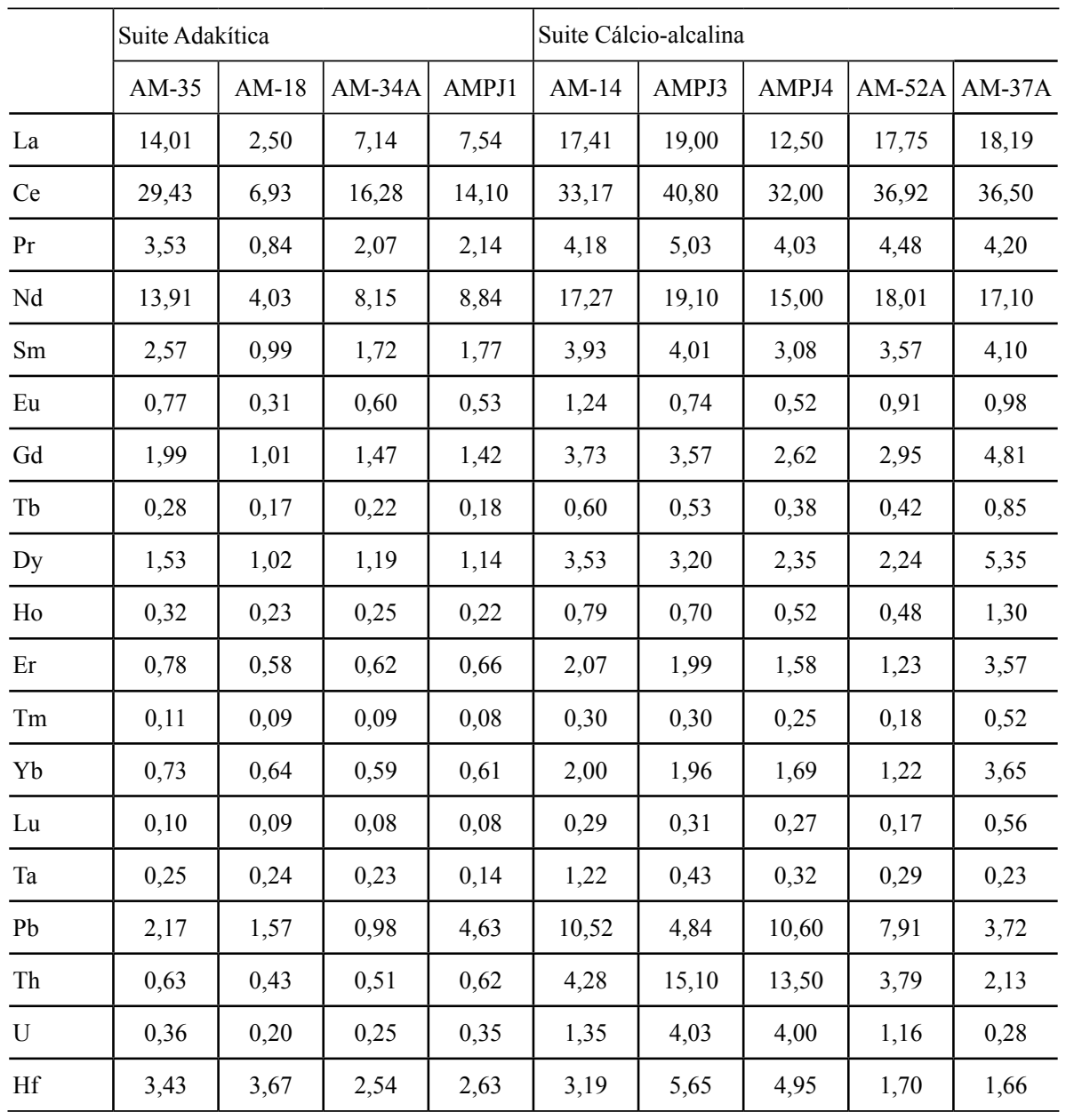
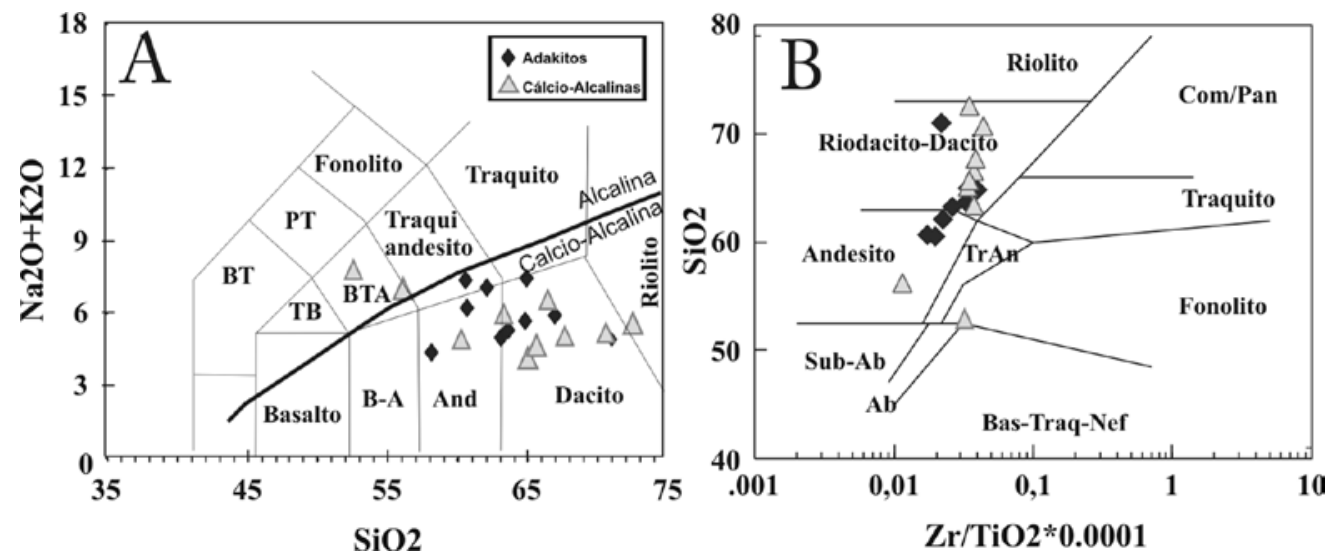

Figura 6 - Diagramas de classificação. Triângulos=cálcio alcalinas (CA), losangos=adakitos (Adk). A) diagrama total álcalis vs silica (Cox et al.1979) e B) Diagrama $\mathrm{SiO}_{2}$ vs $\mathrm{Zr} / \mathrm{TiO}_{2}$ (Winchester \& Floyd 1977).

maior coeficiente de partição para este elemento. Utilizando a expressão $\mathrm{Eu} / \mathrm{Eu}^{*}=\left(2 \mathrm{Eu}_{\mathrm{n}} /\left(\mathrm{Sm}_{\mathrm{n}}+\mathrm{Gd}_{\mathrm{n}}\right)\right)$, que mede o grau de extração de plagioclásio $\left(\mathrm{Eu} / \mathrm{Eu}^{*}<1\right)$ ou acumulação deste mineral $(\mathrm{Eu} / \mathrm{Eu} *>1)$ em um magma, nota-se que os adakitos apresentam valores de $\mathrm{Eu} / \mathrm{Eu}^{*}$ $\sim 1,03$ e as vulcânicas cálcio-alcalinas de aproximada- 

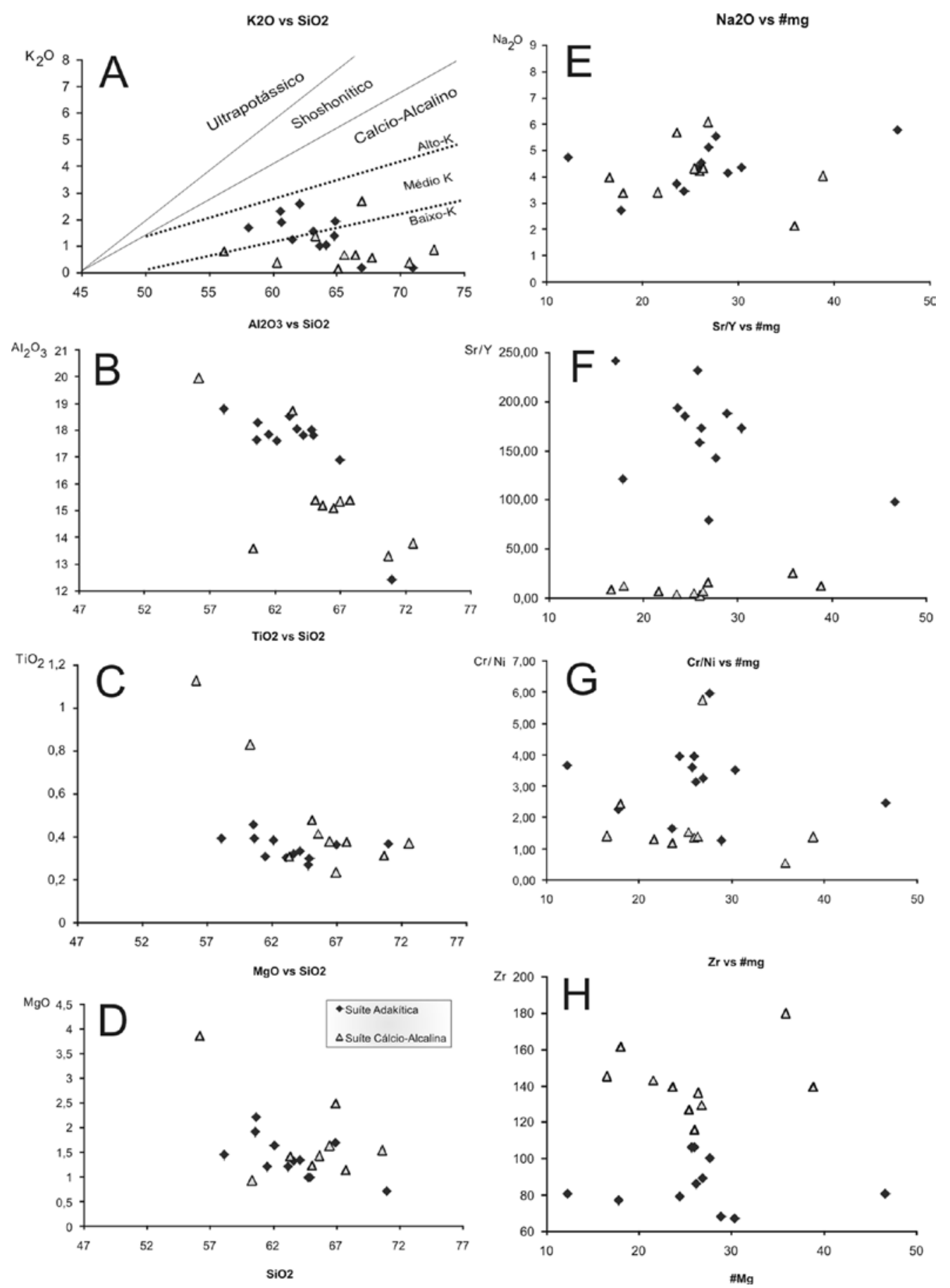

Figura 7 - Diagramas de variação de sílica e número de magnésio (em proporções moleculares) versus diversos elementos e razões. Diagrama $\mathrm{K}_{2} \mathrm{O}$ com campos de Le Maitre (1989).

mente 0,76 . Esses números indicam que deve ter ocorrido extração de plagioclásio durante o esfriamento do magma cálcio-alcalino, ou que este mineral era pouco abundante na fonte ou ficou como resíduo nela durante a fusão parcial. Por outro lado, a ausência de anomalia de Eu nos adakitos sugere que plagioclásio e outro mineral com elevado coeficiente de partição para Sm e Gd (ex. hornblenda) devem ter sido fases no liquidus.

Na tentativa de entender melhor as relações petrogenéticas entre as duas suítes vulcânicas, na figura
10 são apresentados diagramas Sr/Y vs. Y e Ti/Y vs. Zr e vetores de cristalização fracionada. Nesses diagramas aparecem hiatos expressivos nas razões acima, com as rochas adakíticas mostrando razões $\mathrm{Sr} / \mathrm{Y}$ e Ti/Y mais elevadas do que as cálcio-alcalinas. As variações observadas em cada uma das suítes podem ser atribuídas à cristalização fracionada simultânea de hornblenda e plagioclásio, porém é pouco provável que as duas suítes sejam derivadas do mesmo magma. Esta hipótese pode ser avaliada pelas razões iniciais de isótopos de 

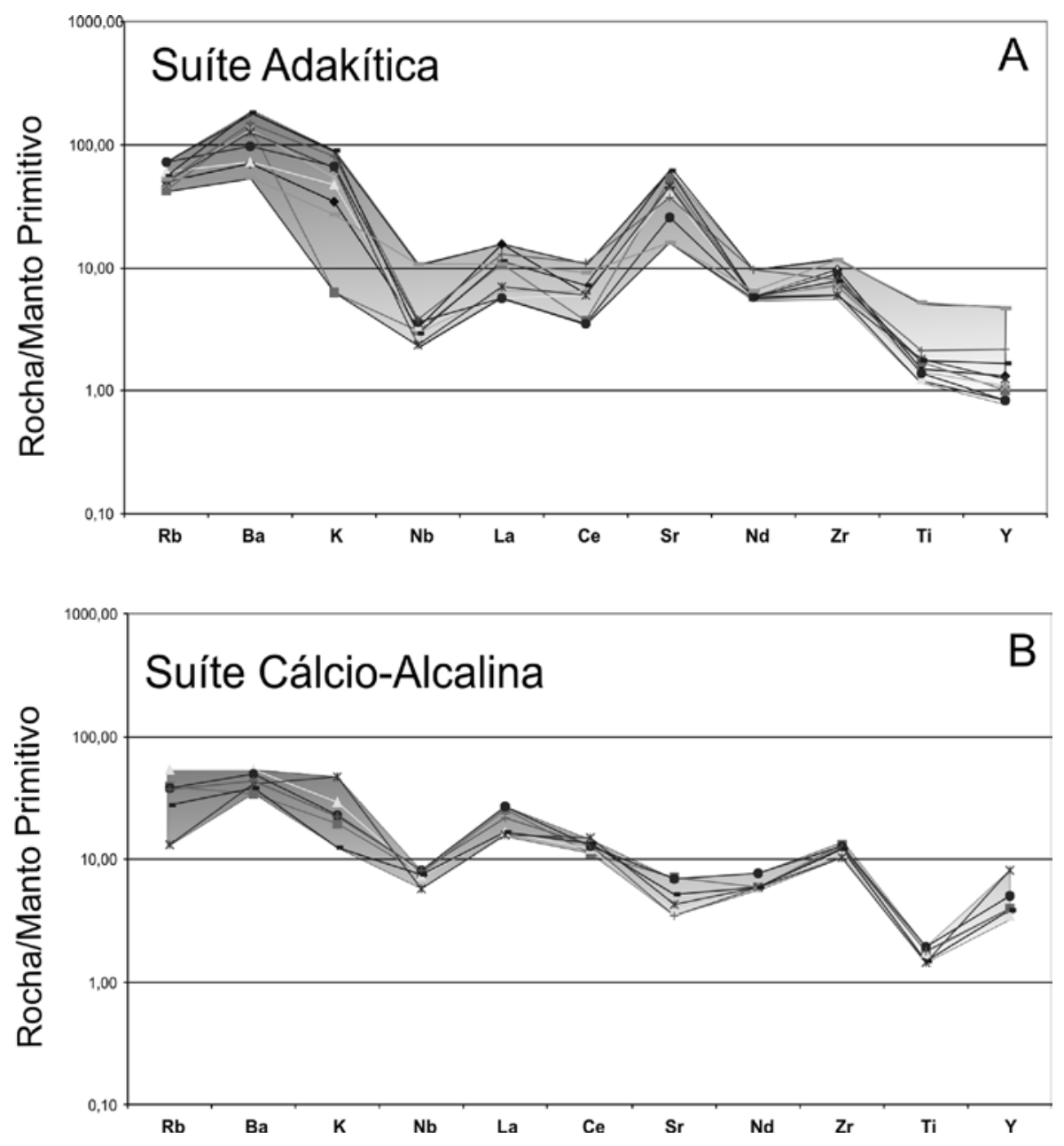

Figura 8 - Diagramas de multi-elementos normalizados ao manto primitivo (valores normativos de McDonough et al. 1992). Notar valores de Rb, Ba, K e Sr maiores nos adakitos e razão $($ Ti $/ Y) n<1$ na suite cálcio-alcalina e $>1$ na suite adakitica.

$\mathrm{Nd}$, apresentadas a seguir.

Isótopos de Sm-Nd Foram feitas seis análises de isótopos de Sm-Nd na Unidade Maria Preta, dentre elas três da suíte cálcio-alcalina e três da suíte adakítica. As análises foram feitas no Laboratório de Geocronologia da Universidade de Brasília, segundo os protocolos analíticos apresentados em Gioia \& Pimentel (2000). Os resultados são apresentados na tabela 4 . As amostras analisadas para estes isótopos também foram analisadas por fluorescência de raios-X e estão representadas na tabela 2.

$\mathrm{Na}$ figura 11 são apresentados os resultados de isótopos de $\mathrm{Nd}$ para as amostras de vulcânicas da Unidade Maria Preta. As razões ${ }^{143} \mathrm{Nd} /{ }^{144} \mathrm{Nd}$ medidas foram recalculadas para a idade de $2170 \mathrm{Ma}$, proposta por Silva (1996), conforme apresentado na tabela 1. Nota-se que as rochas vulcânicas cálcio-alcalinas apresentam razões iniciais praticamente iguais, indicando que devem ter originado de um ou mais magmas com características isotópicas semelhantes. Por outro lado, o mesmo não pode ser assegurado para as rochas vulcânicas adakíticas, que apresentam razões ${ }^{143} \mathrm{Nd} /{ }^{144} \mathrm{Nd}$ iniciais variadas. Esta característica pode ser atribuída

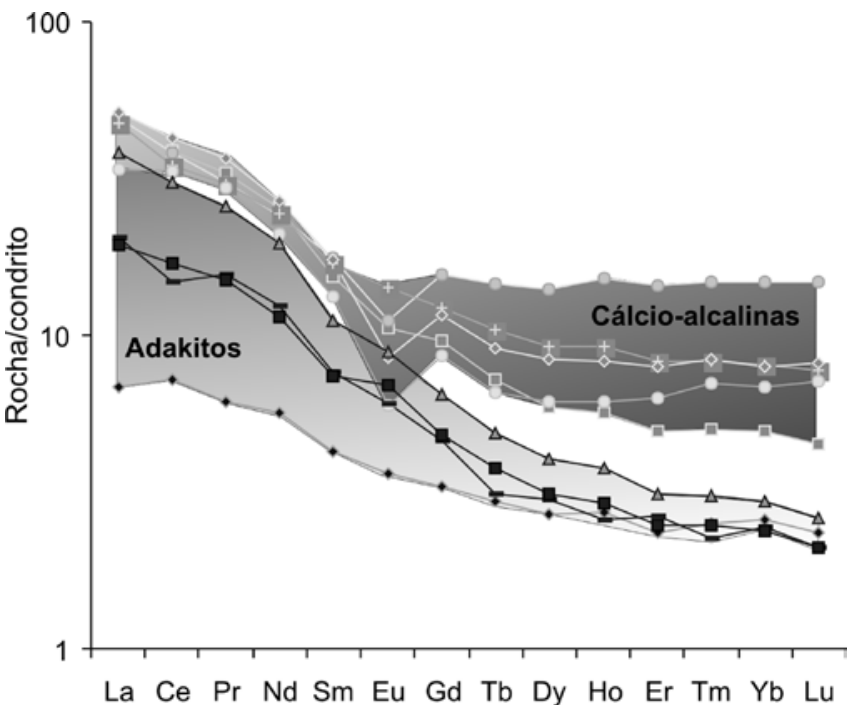

Figura 9 - Diagrama de elementos terras raras normalizados ao condrito (Taylor e Mclennan, 1985). Notar anomalias negativas de Eu para a suite cálcio-alcalina e anomalia levemente positiva de Eu para a suite adakitica. 

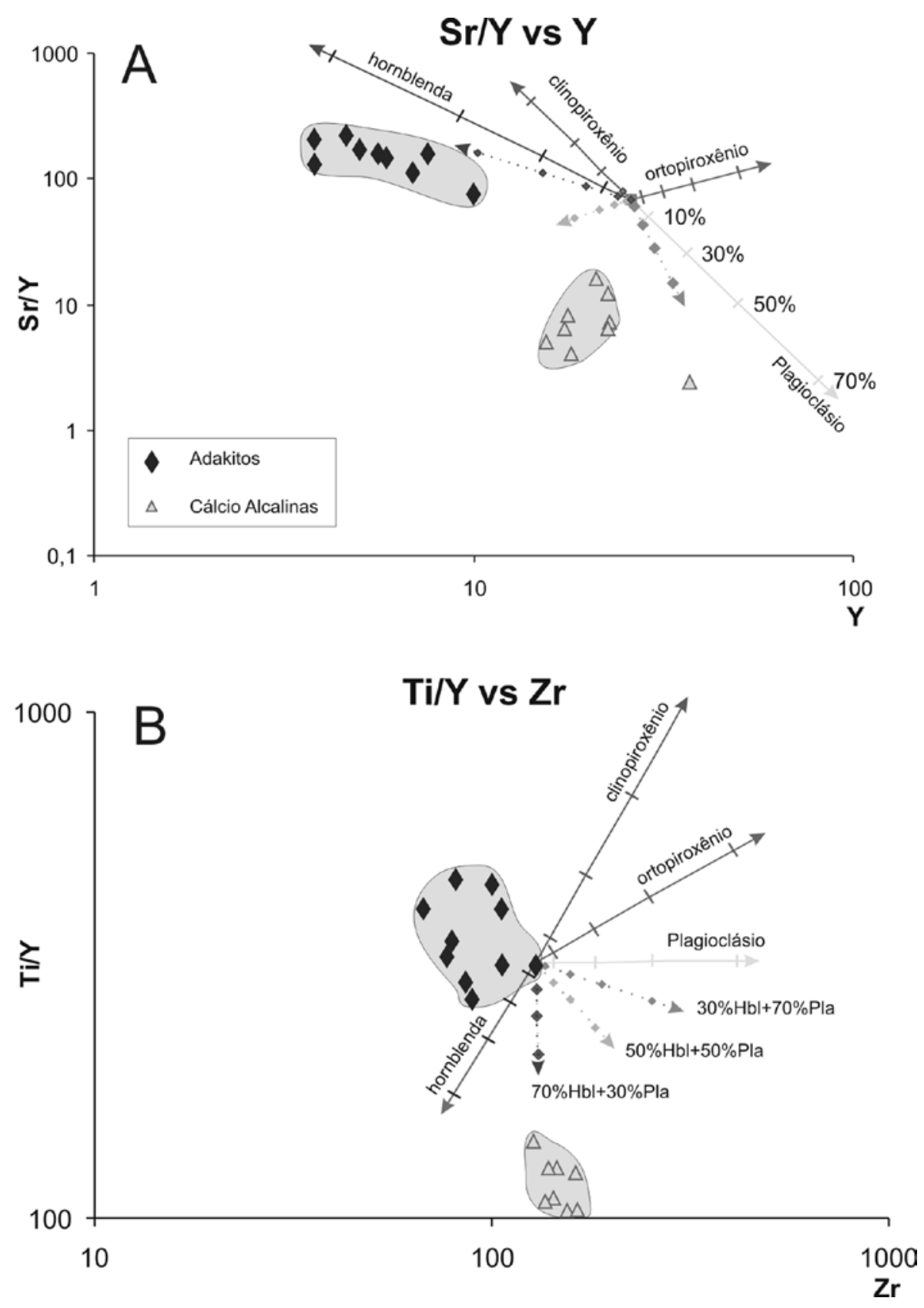

Figura 10 - Diagramas $S r / Y$ vs. $Y(A)$ e Ti/Y vs. $Z r$ (B) com vetores de cristalização fracionada em equilíbrio de plagioclásio, hornblenda, ortopiroxênio, clinopiroxênio e combinações dos dois primeiros. Comprimento dos vetores equivale a $70 \%$ de fracionamento.

Tabela 4 - Resultados das análises de Sm-Nd para a Unidade Maria Preta. Idade Pb-Pb segundo Silva (1992).

\begin{tabular}{|c|c|c|c|c|c|c|c|c|c|}
\hline & & $\mathrm{Pb}-\mathrm{Pb}$ & $\mathrm{Sm}$ & $\mathrm{Nd}$ & ${ }^{147} \mathrm{Sm} /{ }^{144} \mathrm{Nd}$ & ${ }^{143} \mathrm{Nd} /{ }^{144} \mathrm{Nd}$ & $\mathrm{T}_{\mathrm{DM}}$ & $\mathrm{e}_{\mathrm{Nd}}(0)$ & $\mathrm{e}_{\mathrm{Nd}}(\mathrm{t})$ \\
\hline Amostra & Geoquímica & & $\mathrm{ppm}$ & ppm & & $(+-1 \mathrm{~s})$ & $\mathrm{Ma}$ & & \\
\hline AM 14 & Cálcio Alcalina & 2,17 & 3,574 & 16,106 & 0,1342 & 0,51182 & 2330 & $-15,96$ & 1,37 \\
\hline AM 15 & Cálcio Alcalina & 2,17 & 3,898 & 16,167 & 0,1458 & 0,512012 & 2300 & $-12,21$ & 1,90 \\
\hline AM $19 \mathrm{~A}$ & Cálcio Alcalina & 2,17 & 2,847 & 14,141 & 0,1217 & 0,511667 & 2279 & $-18,94$ & 1,85 \\
\hline GBRI-10 & Adakito & 2,17 & 1,805 & 8,974 & 0,12158 & 0,511747 & 2134 & $-17,38$ & 3,45 \\
\hline GBRI-11 & Adakito & 2,17 & 2,882 & 14,041 & 0,12405 & 0,511736 & 2213 & $-17,60$ & 2,55 \\
\hline AM 99 & Adakito & 2,17 & 1,575 & 7,774 & 0,1225 & 0,511829 & 2010 & $-15,78$ & 4,79 \\
\hline
\end{tabular}



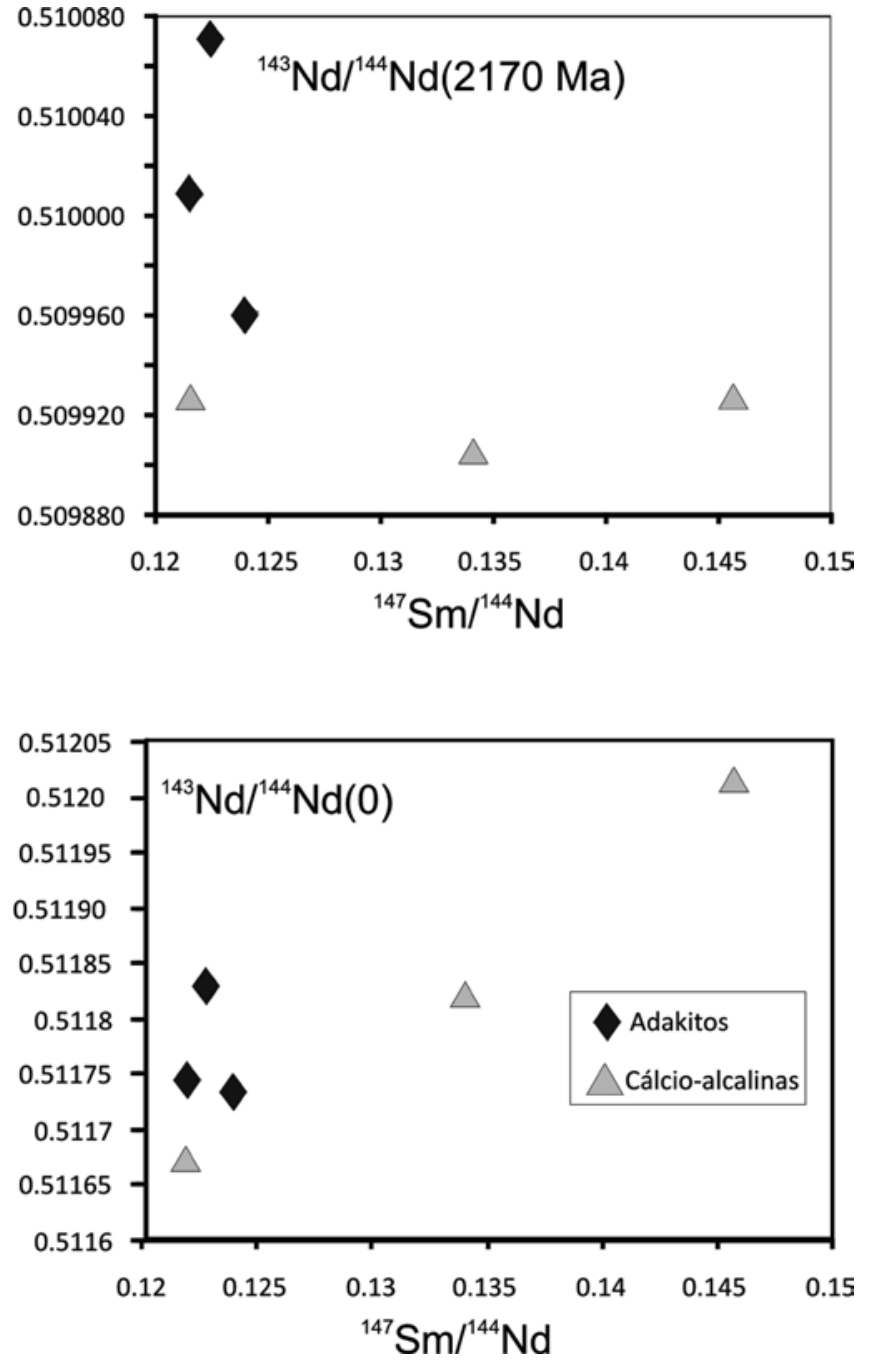

Figura 11 - Diagrama ${ }^{143} \mathrm{Nd} /{ }^{144} \mathrm{Nd} v \mathrm{vs} \cdot{ }^{147} \mathrm{Sm} /{ }^{144} \mathrm{Nd}$ para as rochas vulcânicas da Unidade Maria Preta. Notar razões ${ }^{143} \mathrm{Nd} /{ }^{144} \mathrm{Nd}(i)$ praticamente constantes para a suíte calcio-alcalina e variada para a suite adakitica. à heterogeneidade na fonte que gerou o(s) magma(s) adakítico(s) ou contaminação deste(s) com material crustal durante ascensão na litosfera.

DISCUSSÃO Neste trabalho são descritos, pela primeira vez na região central do Greenstone Belt do Rio Itapicuru, andesitos e dacitos com características geoquímicas de suítes vulcânicas adakíticas e cálcio-alcalinas.

Qualquer discussão sobre a origem dessas suítes deve necessariamente considerar que as rochas (i) foram metamorfisadas em fácies xistos verdes e consequentemente alguns elementos químicos (ex. $\mathrm{Na}, \mathrm{Rb}$ e $\mathrm{K})$ podem ter sido remobilizados, (ii) derivaram de magmas distintos, conforme indicado pelas razões iniciais de isótopos de $\mathrm{Nd}$, (iii) a variação química em cada uma das suítes pode ser atribuída à cristalização fracionada de plagioclásio e anfibólio, e (iv) as rochas adakíticas ocorrem a oeste, próximas ao contato com a unidade basal de basaltos, e as cálcio-alcalinas mais a leste.

Apesar do metamorfismo de baixo grau, apenas uma amostra analisada contém valor relativamente mais alto de $\mathrm{Na}_{2} \mathrm{O}$, enquanto que todas as demais apresentaram variações de elementos mais móveis, ou imóveis, compatíveis com processos de cristalização fracionada a partir de mais de um tipo de magma, isto é, adakítico e cálcio-alcalino. A questão a ser discutida agora é em qual contexto tectônico essas duas suítes podem ter-se originado.

Suítes vulcânicas semelhantes àquelas estudadas aqui ocorrem em ambientes de arcos vulcânicos intra-oceânicos (e.g. Kay 1978, Yamamoto 2007) e de margem continental (e.g. Matteini et al. 2002, Calmus et al. 2006, Hidalgo 2007), e em ambiente pós-colisão continental (Hou et al. 2004, Wang et al. 2005, 2006).

Com o objetivo de avaliar o possível contexto tectônico das duas suites vulcânicas do GBRI, as análises químicas foram plotadas no diagrama $\mathrm{Rb}$ vs. $\mathrm{Y}+\mathrm{Nb}(\mathrm{Pe}-$ arce \& Peate 1995), figura 12, juntamente com análises

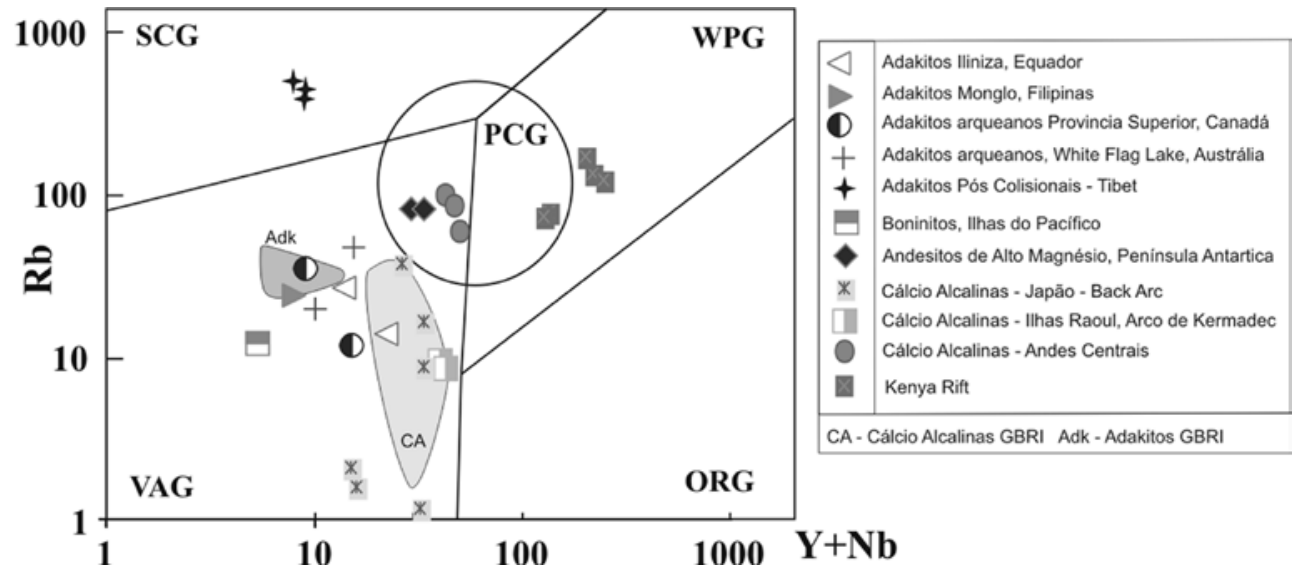

Figura 12 - Diagrama geoquímico classificatório de ambientes tectônicos, segundo Pearce \& Peate (1995), para as rochas vulcânicas do GBRI (campos preenchidos) e rochas similares de ambientes tectônicos conhecidos (referências no texto). VAG - Granito de arco vulcânico, WPG- Granitos intra-placa, SCG - granitos sin-colisionais, ORG - Granitos de dorsais oceânicas e PCG-Granitos pós-colisionais. 
representativas de suites vulcânicas adakíticas e cálcioalcalinas de arcos e de ambiente pós-colisional. Nota-se que as rochas vulcânicas de contextos tectônicos conhecidos situam-se nos campos esperados e aquelas do GBRI posicionam-se no campo de rochas de arco magmático. As rochas adakiticas posicionam-se próximas aos adakitos modernos filipinos e equatorianos (Equador: Iliniza Volcanic Complex, Hidalgo et al. 2007; Monglo, Filipinas - Payot et al. 2007) e próximos também a adakitos arqueanos (Província Superior, Austrália- Percival et al. 2003; White Flag Lake, Australia- Morris \& Witt 1997). A suite cálcio-alcalina se posicionou próxima a rochas cálcio-alcalinas de retro-arco japonesas (Shuto et al. 2006), das ilhas Raoul no arco de Kermadec (Smith et al. 2006) e também de cálcio-alcalinas dos Andes Centrais (Matteini et al. 2002). Este diagrama também faz referência a rochas cálcio-alcalinas de rifte (Kabeto et al. 2001); andesitos de alto magnésio da Península Antartica (Alabaster \& Storey 1990) e a adakitos pós colisionais do Tibet (Guo et al. 2007).

Adakitos são formados pela fusão de basaltos hidratados em pressões suficientemente altas para estabilizar granada+anfibólio no restito e fundir plagioclásio (Rapp \& Watson 1995). Isto pode ocorrer tanto em um ambiente de subducção de crosta oceânica quanto em outros ambientes nos quais seja possível a fusão de crosta máfica hidratada, como, por exemplo, em crosta continental espessada (ex Tibet, Zhao et al. 2007).

Lee et al. (2005) estabeleceram um método para estimar a fugacidade de oxigênio (fO2) no sítio de geração de magmas, que também pode ser utilizado para avaliar se as rochas adakíticas do GBRI formaram por fusão de crosta máfica em ambiente de arco ou de crosta continental espessada. Esses autores utilizaram a razão V/Sc que permite identificar os valores de fO2 independente dos processos pelos quais o magma passou (ex. cristalização fracionada, assimilação crustal, etc). Deste modo (Fig. 13), para a suíte cálcio-alcalina do GBRI, os valores de fO2 variam entre aproximadamente -1 e -3 FMQ (tampão Faialita-Magnetita-Quartzo), e na suíte adakítica entre -1 e +0,5 FMQ. Além disso, as suítes vulcânicas do GBRI situam-se no campo das rochas de arco, porém em dois grupos distintos. Isto provavelmente se deve ao fato de as duas suítes teremse originado de fontes com razões $\mathrm{V} / \mathrm{Sc}$ diferentes, e conseqüentemente com fO2 também distintas, à semelhança do que foi demonstrado pelas razões iniciais de isótopos de Nd. Adakitos gerados em ambiente de fusão de crosta inferior (underplating) possuem maiores valores de $\mathrm{V} / \mathrm{Sc}$ (maiores valores de $\mathrm{fO}_{2}$ ) do que aqueles gerados pela fusão de crosta oceânica (Fig. 13). Os adakitos da Unidade Maria Preta situam-se próximos à média dos adakitos de arco cenozóico (Defant \& Drummond 1990), sugerindo que este também possa ser o contexto tectônico dos adakitos do GBRI.

Experimentos de fusão de meta-basalto hidratado (granada anfibolito ou eclogito) produzem composições muito semelhantes aos adakitos, porém em condições muito específicas: 10 a $40 \%$ de fusão entre 10 e $12 \mathrm{kbar}$, onde a granada fica estável (Rapp et al. 1991,

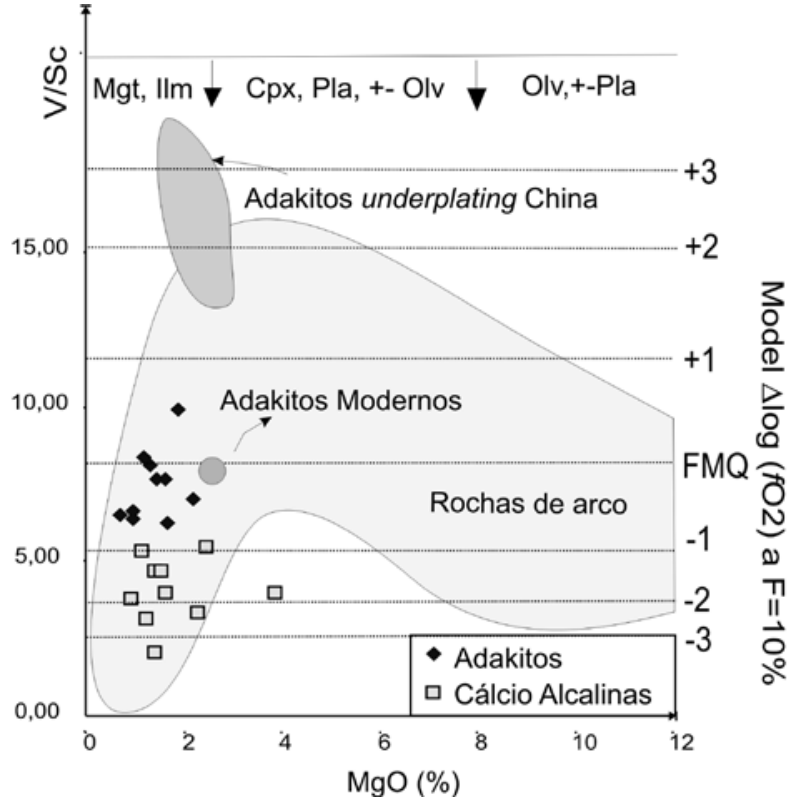

Figura 13 - Diagrama de fugacidade de oxigênio (ordenada à direita) e $\mathrm{V} / \mathrm{Sc}$ vs $\mathrm{MgO}$, com campo para rochas adakíticas e cálcio-alcalinas de arco (segundo Lee et al. 2005). FMQ-índice de fugacidade em relação ao tampão Faialita-Magnetita-Quartzo. As curvas com setas (da direita para a esquerda) correspondem à evolução de magmas de arco quando interagem com crosta continental superior, média e inferior (Rudnick \& Fontain 1995). O campo dos adakitos modernos é de Defant \& Drummond (1994) e o de adakitos gerados pela fusão de crosta inferior (underplating) é de Zhao et al. (2005). $F=10 \%$ de fusão parcial do manto.

Rapp \& Watson 1995). Entretanto, tais experimentos produziram magmas de composição adakítica com $\mathrm{Cr}$ e Ni inferiores aos valores encontrados em adakitos atuais. Para Martin (1999) e Martin et al. (2005), os altos valores de $\mathrm{Cr}$ e $\mathrm{Ni}$ em adakitos atuais sugerem interação entre o magma adakítico e o manto. Esta sugestão é razoável, visto que inclusões de fundido (melt inclusions) em grãos de olivina de xenólitos mantélicos ultramáficos, encontrados em vulcões nas Ilhas Batan e no arco de Kamchatka (Kepezhinskas et al. 1995, 1996), possuem caráter adakítico, sugerindo que os magmas interagiram significativamente com o manto. A suíte adakítica da Unidade Maria Preta apresenta valores baixos de $\mathrm{Cr}$ e Ni em comparação com os adakitos atuais, possivelmente indicando pouca interação do magma adakítico com o manto.

Finalmente, a distribuição das rochas adakíticas e cálcio-alcalinas, na região central do GBRI, pode ser utilizada para especular sobre sentido de subducção de placa oceânica. As vulcânicas adakíticas ocorrem a oeste, próximas ao contato com a unidade máfica basal, e as cálcio-alcalinas mais a leste. Se as rochas vulcânicas adakíticas e cálcio-alcalinas forem aproximadamente da mesma idade e a distribuição espcaial for combinada com as profundidades normalmente admitidas para a 
geração de magmas cálcio-alcalinos e adakíticos em arcos, isto é, os primeiros gerados em profundidades mais rasas do que os últimos, então sugerimos que foi para oeste a subducção da placa oceânica que originou as vulcânicas investigadas. Os valores mais baixos de $\mathrm{Cr}$ e Ni nos adakitos do GBRI, do que em rochas similares cenozóicas, provavelmente indicam que o magma progenitor dessas rochas percorreu uma pequena coluna de manto, ou que a cunha de manto litosférico acima da crosta oceânica subductada era originalmente pequena.

CONCLUSÕES A caracterização geoquímica revelou a existência de dois grupos distintos de lavas intermediárias da Unidade Maria Preta do Greenstone Belt do Rio Itapicuru. Um deles com características semelhantes aos adakitos modernos e outro cálcio-alcalino típico de margens ativa. A geoquímica de elementos traço e os valores de $\varepsilon_{\mathrm{Nd}(\mathrm{T})}$ positivos para as lavas sugerem ambiente de subducção para a formação do magmatismo intermediário a félsico da UMP.

A origem da suíte adakítica é atribuída à fusão parcial de crosta oceânica (metabasalto hidratado) em pressões altas o suficiente para estabilizar granada \pm anfibólito residuais (baixos valores de Y), e fundir plagioclásio (altos valores de $\mathrm{Sr}$ ). A origem das vulcânicas cálcio-alcalinas é atribuída à fusão parcial de peridotito mantélico metassomatizado por fluídos liberados a partir da desidratação de crosta oceânica.

A distribuição regional das rochas vulcânicas adakíticas e cálcio-alcalinas sugere subducção de crosta oceânica de leste para oeste.

Agradecimentos Yamana Gold Inc. pelo acesso aos testemunhos de sondagem e pelo apoio financeiro na fase inicial deste projeto. Ao CNPq por bolsa de estudo de Mestrado ao autor sênior e de produtividade em pesquisa a EPO (CNPq 301025/2005-3). FAPESP (proc. 2006/06222-1) forneceu os recursos necessários à finalização desta pesquisa. Os autores agradecem à Maria Aparecida Vendemiato e Lúcia Helena dos Santos Carvalho pelas análises químicas na Fluorescência de Raios-X do IG-UNICAMP. Ao DMG-IGc-USP pelas análises realizadas no Laboratório de Química e ICP e à Juliana Finotto Bueno e Bárbara Alcântara pelas análises no Laboratório de Geocronologia da UNB.

\section{Referências}

Alabaster T. \& Storey B.C. 1990. Antarctic Peninsula continental magnesian andesites: indicators of ridge-trench interaction during Gondwana break-up. Journal of the Geological Society, 147:595-598.

Alves da Silva F.C. 1994. Etude structurale du Greenstone Belt Paleoproterozoique du Rio Itapicuru (Bahia, Brésil). Tese de Doutoramento, Orleans, Géosciences, Université d'Orleans $340 \mathrm{p}$.

Barrueto H.R. 1997. Intrusões sub-vulcânicas alcalinas e lamprófiros nas mineralizações auríferas do Greenstone Belt do Rio Itapicuru, Bahia: Petrografia, geoquímica e inclusões fluídas. Dissertação de Mestrado, Instituto de Geociência, Universidade Estadual de Campinas, 160 p.

Barrueto H. R. 2002. Petrogênese das intrusões compostas de Teofilândia e Barrocas, Greenstone Belt do Rio Itapicuru, Bahia, Brasil. Tese de Doutoramento, Instituto de Geociências, Universidade Estadual de Campinas, 188.p.

Brito Neves B.B., Cordani U.G., Torquato J.R.F. 1980. Evolução geocronológica do Precambriano do Estado da Bahia. In: Inda H.A.V. \& Duarte F.B. (orgs.) Geologia e Recursos Minerais do Estado da Bahia. Textos Básicos, Salvador, CPM-SME 3:1-101.

Calmus T., Aguillo'n-Robles A., Maury R.C., Bellon H., Benoit M., Cotton J., Bourgois J., Michaud F. 2003. Spatial and temporal evolution of basalts and magnesian andesitos ("bajaites") from Baja California, Mexico: the role of slab melts. Lithos, 66:77-105.

Chauvet A., Guerrot C., Alves da Silva F.C., Faure M. 1997. Géochronologie ${ }^{207} \mathrm{~Pb} /{ }^{206} \mathrm{~Pb}$ et ${ }^{40} \mathrm{Ar} /{ }^{39} \mathrm{Ar}$ des granites paléoprotérozoiques de la ceinture de roches vertes du Rio Iapicuru (Bahia, Brésil). Comptes Rendus de l'Academie des Sciences Paris II , 324:293-300.

Cox K.G., Bell J. D., Pankhurst R. J. 1979. The interpretation of igneous rocks. London: Allen \& Unwin, 450 p.

Corriveau L. \& Gorton M.P. 1993. Coexisting K-rich alkaline and shoshonitic magmatism of arc affinities in the Proterozoic: a reassessment of syenitic stocks in the southwestern Grenville Province. Contrib. Mineral. Petrol., 113:262-279.

Cruz Filho B.E., Rosa M.L.S., Conceição H., Macambira M.J.B., Scheller T., Rios D.C., Marinho M.M. 2003. New $\mathrm{Pb}-\mathrm{Pb}$ evaporation age on zircon of Nordestina batholith, northeast of Bahia state, Brazil. South American Symposium on Isotope Geology, 4, Salvador, vol. II:532-534.

Cruz Filho B.E., Rios D.C., Conceição H., Rosa M.L.S., Marinho M.M. 2005. Litogeoquímica do magmatismo cálcioalcalino paleoproterozóico na porção centro sul do Núcleo Serrinha (Leste da Bahia). In: Simpósio sobre o Cráton do São Francisco, 3, Salvador, Bahia, atas, p. 75-78.

Defant M.J. \& Drummond M.S. 1990. Derivation of some modern arc magmas by melting of young subducted lithosphere. Nature, 347:662-665.

Davison I., Teixeira J.B.G., Silva M.G., Neto M.B.R., Matos F.M.V. 1988. The Rio Itapicuru Greenstone Belt, Bahia, Brazil: Structure and Stratigraphical Outline. PreCambriam Res., 42:1-17.

Donatti Filho J.P. \& Oliveira E.P. 2007. Trace element geochemistry of basalts from the Rio Itapicuru Greenstone Belt, Bahia, and the tectonic setting revisited. In: Simpósio Nacional de Estudos Tectônicos, 11, Natal, p. 296.

Figueiredo M.C.H. 1982. Geochemistry of high-grade complexes of Bahia State, Brazil. Rev. Bras. Geoc., 12(1,2,3):307-312.

Gill J. 1981. Orogenic Andesites and Plate Tectonics. Berlin, Springer-Verlag, $390 \mathrm{p}$. 
Gioia S.M.C.L. \& Pimentel M.M. 2000. The Sm-Nd isotopic method in the geochronology laboratory of the University of Brasília. An. Acad. Bras. Ciênc.,72:219-245.

Guo Z., Wilson M., Liu J. 2007. Post-collisional adakites in south Tibet: Products of partial melting of subductionmodified lower crust. Lithos, 96:205-224.

Hidalgo S., Monzier M., Martin H., Chazot G., Eissen J., Cotton A. 2007. Adakitic magmas in the Ecuadorian Volcanic Front: Petrogenesis of the Iliniza Volcanic Complex (Ecuador). J. Volcanology and Geothermal Research, 159:366-392.

Hou Z.Q., Gao Y.F., Qu X.M., Rui Z.Y., Mo. X.X. 2004. Origin of adakitic intrusives generated during mid-Miocene east-west extension in southern Tibet. Earth and Planetary Science Letters, 220:139-155.

Lee C.A., Leeman W.P., Canil D., Li Z.X. 2005. Similar V/ Sc systematics in MORB and arc basalts: implications for the oxygen fugacities of their mantle source regions. $J$. Petrol., 46:2313-2336.

Le Maitre, Batean P., Dudek A., Keller J., Lamiere J., Le Bas M.J., Sabine P.A., Schmid R., Sorensen H., Streckeisen A., Woolleu A.R., Zanettin B. 1989. A classification of igneous rocks and glossary of terms: Recommendations of the International Union of Geological Sciences Subcomission on the Sustematics of Igneous Rocks. Oxford Blackwell Scientific., 193 p.

Kabeto K., Sawada Y., Wakatsuki T. N., 2001. Mantle sources and magma-crust interactions in volcanic rocks from the northern Kenya rift: geochemical evidence. Lithos, 56:111-139.

Kay R.W. 1978. Aleutian Magnesian Andesites: Melts from subducted Pacific Ocean Crust. Journal of Volcanology and Geothermal Research, 4:497-522.

Kepezhinskas P.K., Defant M.J., Drummond M.S. 1995. Na metasomatism in the island arc mantle by slab melt-peridotite interaction: evidence from mantle xenoliths in the north Kamchatka arc. J. Petrol., 36:1505-1527.

Kepezhinskas P.K., Defant M.J., Drummond M.S. 1996. Progressive enrichment of island arc mantle by melt-peridotite interaction inferred from Kamchatka xenoliths. Geochim. Cosmochim. Acta, 60:1217-1229.

Kishida A 1979. Característica geológica e geoquímica da seqüencia vulcano-sedimentar do médio Rio Itapicuru, Bahia. Dissertação de Mestrado, Instituto de Geociências, Universidade Federal da Bahia, 98 p.

Kishida A. \& Riccio L. 1980. Chemostratigraphy of lava sequences from the Rio Itapicuru Greenstone Belt, Bahia, Brazil. Precambrian Res., 11:161-178.

McDonough W.F., Sun S., Ringwood A.E., Jagoutz E., Hofman A.W.K. 1992. Rb and Cs in the earth and moon and the evolution of the earth's mantle. Geochimica et Cosmochimica Acta, 56:1001-1012.

Mascarenhas J.F. 1979. Evolução geotectônica do Pré cambriano do estado da Bahia. In: Inda H.A.V. (coord.) Geologia e recursos minerais do estado da Bahia. SME/ COM, Bahia, Textos Básicos, 2:55-165.

Martin H., Smithies R.H., Rapp R.J.F., Moyen D., Champion D. 2005. An overview over adakite, tonalite-trondhjemitegranodiorite (TTG) and sanukitoid: relationships and some implications for crustal evolution. Lithos, 79:1-24.
Martin H. \& Moyen J.F. 2002. Secular changes in TTG composition as markers of the progressive cooling of the Earth. Geology, 30:319-322.

Martin H. 1999. The adakitic magmas: modern analogues of Archaean granitoids. Lithos, 46:411-429.

Matteini M., Mazzuoli R., Omarini R., Cas R., Maas R. 2002. Geodynamical evolution of Central Andes at $24^{\circ} \mathrm{S}$ as inferred by magma composition along the Calama-Olacapato-El Toro transversal volcanic belt. J. Volcanology and Geothermal Research, 118:205-228.

Mello E.F., Xavier R.P., McNaughton N.J., Hagemann S.G., Fletcher I., Snee L. 2006. Age constraints on felsic intrusions, metamorphism and gold mineralisation in the Paleoproterozoic Rio Itapicuru greenstone belt, NE Bahia State, Brazil. Miner. Deposita, 40:849-866.

Morris P.A. \& Witt W.K. 1997. Geochemistry and tectonic setting of two contrasting Archaean felsic volcanic associations in the Eastern Goldfields, Western Australia. Precambrian Res., 83:83-107.

Navarro M.S. 2004. A implantação de rotina, e seu refinamento, para a determinação de elementos terras raras em materiais geológicos por ICP-OES e ICP-MS. Aplicação ao caso dos granitóides de Piedade-Ibiúna (SP) e Cunhaporanga (PR). Dissertação de Mestrado, Instituto de Geociências, Universidade de São Paulo, 132 p.

Oliveira E.P., Carvalho M.J., McNaughton N.J. 2004a. Evolução do segmento norte do orógeno Itabuna-Salvador-Curaçá: cronologia da acresção de arcos, colisão continental e escape de terrenos. Geologia USP, Série Científica, 4:41-53.

Oliveira E.P., Windley B.F., McNaughton N.J., Pimentel M., Fletcher I.R. 2004b. Contrasting copper and chromium metallogenic evolution of terranes in the Palaeoproterozoic Itabuna-Salvador-Curaçá orogen, São Francisco craton, Brazil: new zircon (SHRIMP) and Sm-Nd (model) ages and their significance for orogen-parallel escape tectonics. Precambrian Res., 128:143-165.

Oliveira E.P., Donatti Filho J.P., Ruggiero A., Costa F.G. 2007. The birth of the Rio Itapicuru Greenstone Belt, Bahia-Brazil, at a Palaeoproterozoic magma-poor rifted continental margin - a working hypothesis. In: Simpósio Nacional de Estudos Tectônicos, 11, Natal, atas, p. 122-124.

Oliveira E.P. McNaughton N.J., Armstrong R. 2010. Mesoarchaean to Palaeoproterozoic Growth of the Northern Segment of the Itabuna-Salvador-Curaçá Orogen, São Francisco Craton, Brazil. In: Kusky T., Mingguo Z., Xiao W. (eds.) The Evolving Continents: Understanding Processes of Continental Growth", Geological Society of London Special Publication, 338 (no prelo).

Payot D.B., Jego S., Maury R.C., Polve M., Gregoire M., Cleulenner G., Tamayo Jr R.A., Yumul Jr. G.P., Bellom H., Cotten J. 2007. The oceanic substratum of Northern Luzon: Evidence from xenoliths within Monglo adakite (the Philippines). Island Arc, 16:276-290.

Percival J.A., Richard O.S.A., Nicole R. 2003. Archean adakitos froma Ashuanipi Complex, eastern Superior Province, Canada: geochemistry, geochronology and tectonic significance. Contr. Min. Petro., 145:265-280.

Pearce J.A. \& Peate D.W. 1995. Tectonic Implication of the Composition of Volcanic Arc Magmas. Annu. Rev. Earth 
Planet. Sci., 23:251-285.

Rapp R.P., Watson E.B., Miller C.F. 1991. Partial melting of amphibolite/eclogite and the origin of Archaean trondhjemites and tonalites. Precambrian Res., 51:1-25.

Rapp R.P. \& Watson E.B. 1995. Dehydration melting of metabasalt at 8-32 kbar: implications for continental growth and crust- mantle recycling. J. Petrol., 36:891-931.

Rios C.R., Conceição H., Macambira J.B.M., Burgos C.M.G., Peixoto A.A., Cruz Filho B.E., Oliveira L.L., Lisboa M.P. 1998. Granitogênese da parte meridional-oriental do Núcleo Serrinha: idade, petrografia e geoquímica. In: Conceição H., Cruz M.J.M., Sá J.H.S., Sabaté P. (eds.) Contribuição ao estudo dos granitos e rochas correlatas. Publicação especial da Sociedade Brasileira de Geologia, Núcleo Bahia-Sergipe, 5:91-113.

Rios D.C. 2002. A granitogênese no Núcleo Serrinha. Tese de Doutoramento, Instituto de Geociências, UFBA, 239 p.

Rocha Neto M.B. \& Pedreira A.J. 1994. Geologia e recursos minerais do Greenstone Belt do Rio Itapicuru, Bahia. Companhia Baiana de Pesquisa Mineral, Salvador, 4:12.

Rudnick R.L. \& Fountain D.M. 1995. Nature and composition of the continental crust: a lower crustal perspective. Reviews of Geophysics, 33: 267-309.

Samsonov A.V., Bogina M.M., Bibikova E.V., Petrova A., Yu A., Shchipansky A.A. 2005. The relationship between adakitic, calc-alkaline volcanic rocks and TTGs: implications for the tectonic setting of the Karelian greenstone belts, Baltic Shield. Lithos, 79:83-106.

Shuto K., Ishimoto H., Hirahara Y., Sato M., Matsui K., Fujibayashi N., Takazawa E., Yabuki K., Sekine M., Kato M., Rezanov A. I. 2006. Geochemical secular variation of magma source during Early to Middle Miocene time in the Niigata area, NE Japan: Asthenospheric mantle upwelling during back-arc basin opening. Lithos, 86:1-33.

Silva L.C., McNaughton N.J., Melo R.C., Fletcher I.R. 1997. $\mathrm{U}-\mathrm{Pb}$ SHRIMP ages in the Itabuna-Caraíba TTG highgrade Complex: the first window beyond the Paleoproterozoic overprinting of the eastern Jequié craton, NE Brazil. In: SGM, Internacional Symposion on Granites And Associated Mineralizations ISGAM, 2, Salvador, Atas, 282-283.

Silva M.G., Coelho C.E.S., Teixeira J.B.G., Alves da Silva F.C., Silva R.A., Souza J.A.B. 2001. The Rio Itapicuru greenstone belt, Bahia, Brazil: geologic evolution and review of gold mineralization. Mineralium Deposita, 36:345-357.

Silva M.G. 1983. A Seqüência Vulcano-sedimentar do Médio Rio Itapicuru, Bahia: Caracterização Petrográfica, Considerações Petrogenéticas Preliminares e Zoneamento Metamórfico. Salvador. Dissertação de Mestrado, Instituto de Geociências, Universidade Federal da Bahia, Salvador, 88 p.
Silva M.G. 1991. Evidências de uma tectônica de colisão-subducção no Proterozóico Inferior no Nordeste do Estado da Bahia. Simpósio Geologia do Nordeste, 19, Atas, 216-219

Silva M.G. 1992. O Greenstone Belt do Rio Itapicuru: Uma Bacia Back-Arc Fóssil. Rev. Bras. Geoc., 22:157-166.

Silva M.G. 1996. Síntese e interpretação dos dados geocronológicos do terreno granito-greenstone do Rio Itapicuru (BA). Congr. Bras. Geol., 39, SBG, Salvador, Anais, 6:544-548.

Silva L.C., Noce M.C., Lobato L.M. 2000. Dacitic Volcanism in the course of the Rio das Velhas (2800-2690 Ma) orogeny: a brazilian archean analogue (TTD) to the modern adakites. Rev. Bras. Geoc., 30:84-387.

Smith I.E.M., Worthington T.J., Price C.R., Stewart B.R., Maas R. 2006. Petrogenesis of dacite in an oceanic subduction environment: Raoul Island, Kermadec Arc. Journal of Volcanology and Geothermal Research, 156:252-265.

Yamamoto T. 2007. A rhyolite to dacite sequence of volcanism directly from the heated lower crust: Late Pleistocene to Holocene Numazawa volcano, NE Japan. Journal of Volcanology and Geothermal Research, 167:119-133.

Vasconcelos P. \& Becker T. 1992. A idade da mineralização aurífera no depósito da Fazenda Brasileiro, Bahia, Brasil. In: Workshop em Metalogênese: Pesquisas atuais e novas tendências. UNICAMP, Campinas, Boletim de Resumos, p 29.

Xavier R.P. \& Foster R.P. 1999. Fluid evolution and chemical controls in the gold deposit of Fazenda Maria Preta, Rio Itapicuru greenstone belt, Bahia, Brazil. Chemical Geology, 154:133-154.

Wang Q., McDermott F., Xu J.F., Bellon H., Zhu Y.T. 2005. Cenozoic K-rich adakitic volcanic rocks in the Hohxil area, northern Tibet: lower-crust melting in an intracontinental setting. Geology, 33:465-468.

Wang Q., Wyman D.A., Xu J.F., Zhao Z.H., Jian P., Xong X.L., Bao Z.W., Li C.F., Bai Z.H. 2006. Petrogenesis of Cretaceous adakitic and shoshonitic igneous rocks in the Luzong area, Anhui Province (eastern China): implications for geodynamics and $\mathrm{Cu}-\mathrm{Au}$ mineralization. Lithos, 89:424-446.

Winchester J.A. \& Floyd P.A. 1977. Geochemical discrimination of different magma series and their differentiation products using immobile elements. Chemical Geology, 20:325-343.

Zhao Z.H., Xiong X.L., Wang Q., Wyman D.A., Bao Z.W, Bai, Z.H., Qiao Y.L. 2007. Underplating-related adakites in Xinjiang Tianshan, China. Lithos, 102:374-391.

\section{Manuscrito ID 11047 Submetido em 13 de março de 2008 Aceito em 09 de fevereiro de 2010}

